\title{
La opinión consultiva del Tribunal Internacional del Derecho del Mar a la luz del principio de trato especial y diferenciado para Estados en desarrollo*
}

\section{The Advisory Opinion of the International Tribunal for the Law of the Sea in the Light of the Principle of Special and Differential Treatment for Developing States}

\section{J. Nicolás Guerrero Peniche**}

\begin{abstract}
SUMARIO: I. Introducción. II. Los antecedentes del caso. III. La opinión consultiva de la Sala de Controversias de los Fondos Marinos del Tribunal Internacional del Derecho del Mar. IV. Observaciones finales.
\end{abstract}

* Artículo recibido el 15 de julio de 2011 y aprobado para publicación el 28 de septiembre de 2011.

** Se ha desempeñado como asesor jurídico para la Delegación de México ante la Comisión Oceanográfica Intergubernamental de la Organización para la Educación, la Ciencia y la Cultura de las Naciones Unidas (Unesco/COI), como consultor en temas de derecho internacional para la misma Unesco/COI, y como director de Derecho Internacional Público I de la Consultoría Jurídica de la Cancillería Mexicana. Participó en la Audiencia de la Opinión consultiva del Tribunal Internacional del Derecho del Mar como parte de la Delegación de la Unesco/COI. Es maestro y doctor en derecho internacional por el Instituto de Altos Estudios Internacionales y de Desarrollo de la Universidad de Ginebra, Suiza. Lo expuesto en este capítulo representa única y exclusivamente la opinión personal del autor. 
RESUMEN: A pesar de la existencia de un instrumento convencional en la materia, el derecho del mar en general, y lo relativo a la explotación de minerales en la denominada Zona, se encuentra aún en una fase de puesta en práctica y de definición fina de los derechos y obligaciones de los Estados. Uno de los ejemplos que se ha hecho patente es lo relativo a las responsabilidades y obligaciones de aquellos Estados que patrocinan a particulares a fin de llevar actividades de exploración y explotación de los recursos minerales de la Zona. Esta cuestión que se presentó en 2010, conforme a lo establecido en la Convención de las Naciones Unidas sobre Derecho del Mar, ante la Autoridad Internacional de los Fondos Marinos, fue remitida al Tribunal Internacional del Derecho del Mar a fin de que éste la dilucidara. La opinión consultiva que emitió el Tribunal analizó, además de las obligaciones de los Estados en general, aquéllas específicas a los Estados en desarrollo, respondiendo así ampliamente a la cuestión presentada por la autoridad.

Palabras clave: Convención de Naciones Unidas sobre Derecho del Mar, Autoridad Internacional de los Fondos Marinos, Tribunal Internacional del Derecho del Mar, opinión consultiva, actividades en la Zona, obligaciones y responsabilidades de Estados patrocinantes, trato especial y diferenciado para Estados en desarrollo.

ABSTRACT: Notwithstanding the existence of a conventional instrument in the matter, the law of the sea in general and with regard to the exploitation of minerals in the so called Zone, is still in a phase of implementation and precise definition of the rights and obligations of States. One example that has become apparent is with respect to the obligations of States that sponsor individuals to lead the exploration and exploitation of the Zone. This issue was presented in 2010, according to the provisions of UNCLOS, to the International Seabed Authority (ISA), submitted to the International Tribunal for the Law of the Sea so it could be clarified. The advisory opinion of the Tribunal also analyzed the obligations of States in general, those specific to the developing States, largely responding to the question presented by the ISA.

Descriptors: United Nations Convention on the Law of the Sea; International Seabed Authority; International Tribunal for the Law of the Sea; United Nations Convention on the Law of the Sea; Area Activities; Obligations and responsibilities of sponsor States; Special and differential treatment for developing States.

RÉSUMÉ: Malgré l'existence d'un instrument conventionnel en la matière, le droit de la mer en général et à l'égard de l'exploitation des minéraux dans la appelée "Zone ", on trouve encore dans une phase de mise en ceuvre et de définition fine des droits et obligations des États. Un exemple qui est devenu est à l'égard des obligations des ceux Etats qui aide aux particulaires avec l'intention de réaliser des activités d'exploration et exploitation de la Zone. Cette question, présentée en 2010, en relation aux dispositions de la CNUDM, devant l'Autorité internationale des fonds marins (AIFM), a été renvoyé à la Cour internationale de droit de la mer afin qu'elle soit clarifiée. L'avis consultatif de la Cour a analysé les obligations des Etats en général, et celles spécifiques aux États en développement, en répondant à la question posée par l'AIFM.

Mots-clés: l'Autorité internationale des fonds marins, Court international du droit de la mer, Chambre pour le règlement des différends relatifs aux fonds marins, Convention des Nations Unies sur le droit de la mer, Activités dans la Zone, l'exploitation des nodules polymétalliques, les obligations et responsabilités des Etat appuis, Le traitement spécial et différencié pour les pays en développement. 


\section{INTRODUCCIÓN}

Como muchas otras áreas del derecho internacional, hasta la década de 1960, la normativa aplicable al mar había sido exclusivamente desarrollada sobre la base de la práctica de las potencias europeas, y por ende respondía a sus intereses y necesidades.

Por ello, no es sorprendente que los Estados africanos y asiáticos que se independizaron en las décadas de los sesenta y setenta, y que percibían estas normas como contrarias a sus intereses y favorables a aquéllos de los Estados desarrollados y sus empresas, buscaban el establecimiento de un sistema que favoreciera más sus intereses y que garantizara una repartición equitativa de los beneficios de la explotación de los recursos marinos.

Sin lugar a dudas, el mayor logro de la "revisión" de la normativa aplicable al mar y sus recursos lo constituye el reconocimiento de los fondos marinos como patrimonio común de la humanidad. ${ }^{1}$ La declaración de estas áreas como patrimonio común de la humanidad tenía un doble propósito jurídico; en primer lugar, detener la expansión gradual de la jurisdicción de los Estados ribereños sobre los recursos de los fondos marinos, y, en segundo lugar, y como consecuencia directa de esta declaración, el otorgar a los Estados en desarrollo la posibilidad de recibir parte de los beneficios derivados de estas actividades mineras, para la que no contaban ni con el financiamiento ni la tecnología necesarias. ${ }^{2}$

1 La intervención que llevó a cabo el embajador de Malta, Arvid Pardo, en 1967, ante la Asamblea General de la ONU, marcó el inicio de los cuestionamientos de los Estados en desarrollo sobre la normativa aplicable al mar y sus recursos. El embajador Pardo propuso la inclusión en la agenda de ese organismo de un proyecto de "Declaración y Tratado internacional relativa a la reserva para usos exclusivamente pacíficos de los Fondos Marinos y el suelo del Océano; fundamentalmente los mares más allá de los límites de la jurisdicción actual, y el uso de sus recursos para el beneficio de la humanidad”. Véase UN Doc. A/6695, 17 de agosto de 1967. Una copia de la "Nota verbal” del embajador Pardo al Secretario General de la ONU está contenida en Brown, E.D., The International Law of the Sea, vol. 2, Documents, Cases, and Tables, 1994, Dartmouth, Aldershot, pp. 333 y 334.

Oda, S., "Sharing of Ocean Resources - Unresolved Issues in the Law of the Sea", en Dupuy, R-J (ed.), The Management of Humanity's Resources: The Law of the Sea, Workshop of the Hague Academy of International Law, 29-31 de octubre de 1981, 1982, La Haya, Martinus Nijhoff, p. 53. 
Los esfuerzos iniciales de los Estados en desarrollo se concretizaron en una solicitud formal a la Asamblea General de la Organización de las Naciones Unidas (Asamblea General de la ONU) de convocar una conferencia internacional a fin de revisar la totalidad del régimen jurídico del derecho del mar. ${ }^{3}$

Sobre la base de este ímpetu, a finales de 1970, la Asamblea General de la ONU adoptó la "Declaración de los Principios que rigen los Fondos Marinos y el suelo oceánico, y el subsuelo subyacente, más allá de los límites de la jurisdicción nacional.” A fin de implementar estas disposiciones, la Declaración también hacía un llamado para establecer un régimen internacional aplicable a los fondos marinos y sus recursos. ${ }^{4}$

Fue así que, en 1973, la Asamblea General de la ONU decidió convocar a una conferencia sobre el derecho del mar a fin de que ésta abordara el régimen jurídico de la totalidad de las áreas marinas:

3 Véase "Examination of the question of the reservation exclusively for peaceful purposes of the sea-bed and the ocean floor, and the subsoil thereof, underlying the high seas beyond the limits of present national jurisdiction, and the use of their resources in the interest of mankind", 18 de diciembre de 1967, A/RES/2340(XXII). El Comité ad hoc fue posteriormente transformado en un órgano permanente a través de la resolución relative al "Examination of the question of the reservation exclusively for peaceful purposes of the sea-bed and the ocean floor, and the subsoil thereof, underlying the high seas beyond the limits of present national jurisdiction, and the use of their resources in the interest of mankind", 21 de deciembre de 1968, A/RES/2467(XXIII). Véase igualmente las propuestas de los delegados de Jamaica y Trinidad y Tobago relativas al régimen del derecho del Mar en su conjunto, UN Doc. A/C.1/L475. La propuesta fue retomada en 1970 por la 3a. Conferencia de Jefes de Estado y de Gobierno del Movimiento de los Países no Alineados. La Conferencia señaló que "los países en desarrollo se han ganado el derecho de revisar la totalidad del derecho del Mar en una Conferencia que analice de forma exhaustiva, cuestione, destruya si necesario, y crea un régimen nuevo, equitativo, y racional para los fondos marinos y el océano profundo" [traducción libre del autor]. Véase UN. Doc. A/AC 138/34, 30 de abril de 1971, p. 5. En relación a los fondos marinos en particular, la Conferencia apoyó la instauración de un régimen jurídico que "establezca un desarrollo ordenado y una administración razonable de la Zona y sus recursos, garantizando una repartición equitativa por la comunidad internacional de los beneficios derivados de esta actividad" [traducción libre del autor]. Véase "Third Conference of Heads of State or Government of non-aligned countries: Lusaka, September 8-10, 1970" en Two Decades of Non-Alignment: Documents of the Gatherings of the Non-Aligned Countries 1961-1982, 1983, Ministry of External Affairs, Government of India, New Delhi, p. 58.

4 A/RES/2749(XXV), del 17 de diciembre de 1970. 
el establecimiento de un régimen internacional equitativo... para la Zona y los recursos de los fondos marinos y suelo oceánico, y el subsuelo subyacente, más allá de los límites de la jurisdicción nacional... así como de una amplia gama de temas relacionados incluyendo aquellos relativos a los regímenes de la Alta Mar, la Plataforma Continental, el Mar territorial... y la Zona contigua, la pesca y la conservación de los recursos vivos de Alta Mar... y la preservación del medio ambiente marino... y la investigación científica marina (traducción libre del autor). ${ }^{5}$

Esta convocatoria dio origen a la serie de tres conferencias sobre derecho del mar que concluyeron, en 1982, con la adopción de la Convención de las Naciones Unidas sobre el Derecho del Mar (Convemar).

Desde un inicio las demandas de los Estados en desarrollo tendían al establecimiento de un régimen jurídico que garantizara una repartición equitativa de los beneficios derivados de la explotación de los recursos que se encontraban fuera de las áreas de jurisdicción nacional. ${ }^{6}$ Las negociaciones fueron largas y confrontaron abiertamente a los Estados en desarrollo y los desarrollados.

En el texto de la Convemar, adoptado en 1982, los Estados en desarrollo lograron imponer el peso de su mayoría numérica; lo que tuvo como consecuencia que varios Estados se negaran a firmar la Convención. Esta negativa concluyó con al adopción, 12 años después, de un Acuerdo sobre la aplicación de la normativa relativa a la Zona y la explotación de sus recursos.

Si bien este Acuerdo fragilizó el régimen jurídico establecido en la Parte XI de la Convemar, también permitió que la Convención se con-

5 "Reservation Exclusively for Peaceful Purposes of the Seabed and Ocean Floor, and the Subsoil thereof, Underlying the High Seas Beyond the Limits of Present National Jurisdiction and use of their resources in the interest of Mankind, and Convening of a Conference on the Law of the Sea" A/RES/2750(XXV), 17 de diciembre de 1970.

6 Los temores de los Estados en desarrollo quedaron reflejados en la Nota verbal que el Emb. Pardo dirigió en 1967 al secretario general de la ONU y que acompañaba su propuesta. Véase "Note verbale", en Brown, E. D., The International Law of the Sea, cit. Adicionalmente, los Estados en desarrollo buscaban a través de estas medidas controlar y menguar algunos de los efectos negativos que las actividades en los fondos marinos tendrían en los precios de las materias primas que ellos mismos producían. Véase Morris, M. A., "The New International Economic Order and the New Law of the Sea", en Sauvant, K. P. y Hasenpflug, H. (eds.), The New International Economic Order: Confrontation or Cooperation between North and South?, Londres, Wilton House Publications, 1977, p. 17. 
virtiera en un instrumento ampliamente aceptado por la comunidad internacional, como lo prueba el importante número de Estados Parte con los que cuenta hoy en día. ${ }^{7}$

Es así que desde su entrada en vigor, en 1994, la Convemar es el marco jurídico incuestionable que regula las actividades mineras en los fondos marinos. En particular es la Autoridad Internacional de los Fondos Marinos (la Autoridad) quien está mandatada por la Convemar para que en nombre de la humanidad administre los recursos de la Zona.

Sobre la base de este mandato, el 6 de mayo de 2010, el Consejo de la Autoridad Internacional de los Fondos Marinos decidió, durante su 16a. Sesión, y de conformidad con el Artículo 191 de la Convemar, solicitar a la Sala de Controversias de los Fondos Marinos del Tribunal Internacional del Derecho del Mar (la Sala de los Fondos Marinos) una opinión consultiva sobre tres cuestiones jurídicas relativas a las responsabilidades y obligaciones de los Estados patrocinantes de actividades en áreas reservadas de la Zona.

Como se analizará en detalle, el fondo de la solicitud está directamente ligado con el principio de trato especial y diferenciado para Estados en desarrollo cristalizado en la Convemar.

El estudio que se llevará a cabo tendrá entonces como hilo conductor precisamente el examen de la relación entre las obligaciones de los Estados que patrocinan actividades en la Zona y las disposiciones de trato especial y diferenciado previstas en la Convemar. Esto nos permitirá poner en contexto la opinión emitida por el Tribunal a fin de determinar si respondió cabalmente a la solicitud de la Autoridad Internacional de Fondos Marinos.

Este ejercicio requiere analizar en detalle, no sólo el contenido de la opinión consultiva del Tribunal, sino también los antecedentes de la solicitud presentada por la Autoridad y lo establecido en la Convemar en relación a la sustancia de la misma.

\footnotetext{
7 Hasta noviembre de 2010 la Convemar contaba con 161 Estados parte. Fuente: http:// www.un.org/Depts/los/.
} 
Si bien el procedimiento inició con la solicitud de opinión consultiva que formuló el Consejo de la Autoridad Internacional de los Fondos Marinos al Tribunal Internacional del Derecho del Mar, a fin de estar en posibilidades de analizar el caso en su conjunto, resulta necesario examinar los actos que llevaron al Consejo a adoptar esta decisión.

Para entender el contenido de esta solicitud, resulta particularmente importante examinar su origen, los argumentos de los Estados que presentaron esta solicitud, y las negociaciones que llevaron a la adopción de las tres preguntas formuladas por la Autoridad al Tribunal. El examen de estos elementos nos permitirá poner en contexto la solicitud, y entender la problemática jurídica existente alrededor del tema del patrocinio de particulares para llevar acabo actividades en la Zona.

1. El patrocinio de Nauru para actividades en un área reservada y la solicitud de opinión consultiva formulada por el Consejo de la Autoridad Internacional de los Fondos Marinos

La Convemar define la Zona como "los fondos marinos y oceánicos y su subsuelo fuera de los límites de la jurisdicción nacional”, ${ }^{8}$ y la considera junto con sus recursos como patrimonio común de la humanidad. ${ }^{9}$

Ello implica que "Todos los derechos sobre los recursos de la Zona pertenecen a toda la humanidad" y que por ende "Ningún Estado podrá reivindicar o ejercer soberanía o derechos soberanos sobre parte alguna de la Zona o sus recursos, y ningún Estado o persona natural o jurídica podrá apropiarse de parte alguna de la Zona o sus recursos". ${ }^{10}$

A fin de organizar y controlar las actividades de exploración y explotación de los recursos de la Zona, la Convemar estableció un órgano: la Autoridad Internacional de Fondos Marinos, la cual actúa entonces en

\footnotetext{
8 Artículo 1, Convemar.

9 Artículo 136, Convemar.

10 Artículo 137, Convemar.
} 
nombre de la humanidad con miras a la administración de los recursos de la Zona. ${ }^{11}$

La Autoridad está constituida por tres órganos: la Asamblea, el Consejo y la Secretaría. ${ }^{12}$ La Asamblea es el órgano supremo de la Autoridad y está integrada por todos sus miembros. ${ }^{13}$ Por su parte, el Consejo es el órgano ejecutivo de la Autoridad y está integrado por 36 de sus miembros elegidos por un complejo sistema que busca asegurar el equilibrio de representación de las varias categorías de Estados y de sus grupos regionales. ${ }^{14}$

Entre las facultades otorgadas al Consejo se encuentra la de ejercer "control sobre las actividades en la Zona, de conformidad con el párrafo 4 del artículo 153 y las normas, reglamentos y procedimientos de la Autoridad”. ${ }^{15}$ Es por ello que la propuesta presentada al secretario general de la Autoridad Internacional de los Fondos Marinos por la República de Nauru de solicitar una opinión consultiva fue analizada en el marco de este órgano. ${ }^{16}$

Como se verá a continuación, la propuesta original de Nauru presentaba un locus standi ratione materiae considerablemente más amplio que aquel finalmente adoptado por el Consejo. Sin duda, los cambios introducidos a la propuesta de Nauru fueron el resultado de las discusiones y negociaciones en el seno de ese órgano. ${ }^{17}$

En esta sección se analizarán entonces, subsecuentemente, la propuesta de Nauru, las negociaciones en el seno de la Autoridad Internacional de los Fondos Marinos tendientes a la adopción de la decisión de solicitar una opinión consultiva, así como el contenido de esa decisión.

11 Artículo 157, Convemar.

12 Artículo 158, Convemar.

13 Artículo 159 y 160, Convemar.

14 Artículos 161 y 162, Convemar.

15 Artículo 162.2(l), Convemar.

16 La propuesta de Nauru fue incluida como el punto 7 de la agenda de la 16a. Sesión del Consejo en 2010. Véase ISBA/16/C/1 del 27 de abril de 2010.

17 Véase la Memoria que presentó la Autoridad Internacional de los Fondos Marinos ante el Tribunal Internacional del Derecho del Mar en seguimiento a la orden del presidente de la Sala del 18 de mayo de 2010 y de conformidad con el artículo 131 de las Reglas de Procedimiento del Tribunal, Dossier núms. 3 y 4. 


\section{A. Los patrocinios para actividades en la Zona en general}

y en las "áreas reservadas" en particular.

El Anexo III de la Convención detalla las condiciones básicas para la prospección, exploración y explotación de los recursos de la Zona, aplicables a todos los contratistas así como el procedimiento y las condiciones contractuales establecidas en los planes de trabajo previstos en el artículo 153 de la Convención. No obstante, las disposiciones del Anexo III fueron enmendadas por el "Acuerdo relativo a la aplicación de la Parte XI de la Convención de las Naciones Unidas sobre el Derecho del Mar del 10 de diciembre de 1982" (Acuerdo de 1994). ${ }^{18}$ Sobre la base de estas disposiciones enmendadas, el "Reglamento sobre prospección y exploración de nódulos polimetálicos en la Zona” (Reglamento de nódulos) fue adoptado por la Autoridad Internacional de Fondos Marinos. ${ }^{19}$

El Reglamento de nódulos fue adoptado por el Consejo en cumplimiento con lo establecido en el artículo 162 de la Convención, que establece que como parte de sus funciones legislativas ese órgano recomendará a la Asamblea la adopción de "normas, reglamentos y procedimientos sobre la distribución equitativa de los beneficios financieros y otros beneficios económicos derivados de las actividades en la Zona y sobre los pagos y contribuciones que deban efectuarse", con prioridad expresa a aquéllos relativos a los nódulos polimetálicos. ${ }^{20}$

El Reglamento de nódulos, que consta de 40 artículos divididos en 9 partes y 4 anexos, establece las condiciones para la prospección y el procedimiento para el ulterior depósito y aprobación de un plan de trabajo

18 "Acuerdo relativo a la aplicación de la Parte XI de la Convención de las Naciones Unidas sobre el Derecho del Mar de 10 de diciembre de 1982”, adoptado por la Asamblea General de la ONU a través de la Resolución A/RES/48/263 del 28 de julio de 1994.

19 El Reglamento fue adoptado por el Consejo y la Asamblea de la Autoridad Internacional de Fondos Marinos el 13 de julio de 2000, ISBA/6/C/12 e ISBA/6/A/18.

20 Artículo 162(o)(i) y (ii), Convemar. No obstante, resulta procedente recordar que estas disposiciones fueron igualmente afectadas por el Acuerdo de 1994, en particular por el párrafo 5(f) de la Sección 1 del Anexo, que establece que al adoptar estos reglamentos la autoridad deberá tener "en cuenta las disposiciones de este Acuerdo, el retraso prolongado de la explotación minera comercial de los fondos marinos y el ritmo probable de las actividades que se realicen en la Zona”. 
para la exploración de nódulos polimetálicos, así como los términos y condiciones para la eventual firma de un contrato de explotación. ${ }^{21}$

La Convemar instituye un "sistema paralelo" de explotación de los recursos de la Zona. Este sistema establece que la explotación puede llevarse a cabo, de forma simultánea, por la Empresa y por Estados Parte a través de empresas estatales, personas naturales o jurídicas que posean la nacionalidad de ese Estado Parte o que sean efectivamente controladas por ellos o por sus nacionales, o por cualquier agrupación con operadores comerciales privados. ${ }^{22}$

Las condiciones del patrocinio por los Estados Parte están explicitadas en el Anexo III de la Convención, donde se establece que:

Cada solicitante será patrocinado por el Estado Parte del que sea nacional, a menos que tenga más de una nacionalidad, como las asociaciones o consorcios de entidades o personas nacionales de varios Estados, en cuyo caso todos los Estados Partes de que se trate patrocinarán la solicitud, o que esté efectivamente controlado por otro Estado Parte o sus nacionales, en cuyo caso ambos Estados Partes patrocinarán la solicitud. ${ }^{23}$

En este sentido, la Convención establece que a fin de calificar como solicitante para las actividades en la Zona se deberán cumplir 3 requisitos: i) los requisitos de nacionalidad o control; ii) el requisito de patrocinio, y iii) los criterios de aptitud establecidos en las normas, reglamentos y procedimientos de la Autoridad relativos a la capacidad financiera y técnica del solicitante y a la forma en que haya cumplido contratos anteriores con la Autoridad. ${ }^{24}$

En lo que se refiere a las actividades en la Zona, éstas se realizarán con arreglo a un plan de trabajo, que tendrá la forma de un contrato, y que deberá ser aprobado por el Consejo tras su examen por la Comisión Jurídica y Técnica. ${ }^{25}$ El procedimiento para el depósito de solicitudes

\footnotetext{
21 Partes I a V, Reglamento de nódulos.

22 Artículo 153 (2), Convemar.

23 Artículo 4 (3), Anexo III, Convemar.

24 Artículo 4 (1) y (2), Anexo III, Convemar.

25 Artículo 153 (3), Convemar.
} 
para la aprobación de un plan de trabajo para la exploración está previsto en la Parte III y en el Anexo 2 del Reglamento de nódulos.

La Convemar establece que "Los criterios y procedimientos de aplicación de los requisitos de patrocinio se establecerán en las normas, reglamentos y procedimientos de la Autoridad". ${ }^{26}$ Sobre esta base, el Reglamento de nódulos desarrolla en detalle estos criterios, señalando que toda solicitud para la aprobación de un plan de trabajo irá acompañada de un certificado de patrocinio expedido por el o los Estado del cual el solicitante sea nacional o a cuyo control o el de sus nacionales esté efectivamente sujeto. Los certificados de patrocinio serán debidamente firmados en nombre del Estado que los presente y consignarán lo siguientes elementos:

a) El nombre del solicitante;

b) El nombre del Estado patrocinador;

c) Una declaración de que el solicitante:

i) Es nacional del Estado patrocinador; o

ii) Está sujeto al control efectivo del Estado patrocinador o sus nacionales;

d) Una declaración de que el Estado patrocina al solicitante;

e) La fecha en que el Estado patrocinador depositó el instrumento de ratificación, adhesión o sucesión con respecto a la Convención;

f) Una declaración de que el Estado patrocinador asume la responsabilidad a que se hace referencia en el artículo 139 y en el párrafo 4 del artículo 153 de la Convención, y en el párrafo 4 del artículo 4 del anexo III de ésta. ${ }^{27}$

En lo relativo a las áreas objeto de las solicitudes, la Convemar prevé un sistema que se ha denominado de site-banking por el que cada solicitud, con excepción de las presentadas por la Empresa o por cualesquiera otras entidades o personas respecto de áreas reservadas, abarcará en total un área "lo bastante extensa y de suficiente valor comercial estimado para permitir dos explotaciones mineras". El solicitante dividirá el área en "dos partes de igual valor comercial estimado y presentará

26 Artículo 4 (3), Anexo III, Convemar.

27 Artículo 11, Reglamento de nódulos. 
todos los datos que haya obtenido con respecto a ambas partes del área” en relación con los nódulos polimetálicos. ${ }^{28}$

De conformidad con lo previsto por el Reglamento de nódulos, corresponderá al Consejo, previa recomendación de la Comisión Jurídica y Técnica, designar cuál de las dos partes del área se reservará exclusivamente para la realización de actividades por la Autoridad, mediante la Empresa o en asociación con Estados en desarrollo. ${ }^{29}$ El área designada pasará a ser "área reservada" tan pronto como se apruebe el plan de trabajo para el área no reservada y se firme el contrato.

El mecanismo de "áreas reservadas" constituye una parte esencial del principio contenido en la Convemar por el que se reconoce que los recursos de la Zona son patrimonio común de la humanidad. Sobre esta base, el mecanismo tiene como finalidad la creación de áreas de explotación minera en las cuales únicamente la Autoridad Internacional de Fondos Marinos, como administradora en nombre de la humanidad de las actividades de exploración y explotación de los recursos de la Zona, podrá explotar estos recursos. Para ello, la Autoridad podrá actuar a través de la Empresa o en asociación, exclusivamente, con Estados en desarrollo. ${ }^{30}$

Sin embargo, es necesario señalar que la adopción del Acuerdo de 1994 enmendó el mecanismo establecido en la Convemar. Así, mientras que la Convemar dotaba a la Empresa de un derecho de preeminencia sobre la realización de actividades en las áreas reservadas, ${ }^{31}$ el Acuerdo de 1994 establece, por el contrario, que el contratista que haya aportado un área determinada a la Autoridad como área reservada "tiene derecho de opción preferente a concertar un arreglo de empresa conjunta con la Empresa para la exploración y explotación de esa área”. Adicionalmente, en caso de que pasados 15 años del inicio de sus funciones, o 15 años de la fecha en que se haya reservado el área, la Empresa no presente una solicitud de aprobación de un plan de trabajo para la realización de actividades respecto de esa área "el contratista que haya aportado el área tendrá derecho a solicitar la aprobación de un plan de trabajo respec-

28 Artículo 8, Anexo III, Convemar.

29 Artículo 16, Reglamento de nódulos.

30 Artículo 8, Anexo III, Convemar.

31 Artículo 9, Anexo III, Convemar. 
to de ésta a condición de que ofrezca de buena fe incluir a la Empresa como socio en una empresa conjunta". ${ }^{32}$

Sobre esta base, el Reglamento de nódulos establece que

Todo Estado en desarrollo o toda persona natural o jurídica patrocinada por él y que esté bajo su control efectivo o bajo el de otro Estado en desarrollo, o toda agrupación de los anteriores, podrá notificar a la Autoridad su intención de presentar un plan de trabajo para la exploración respecto de un área reservada.

La Empresa contará entonces con 6 meses para decidir si tiene o no intención de realizar actividades en esa área reservada. ${ }^{33}$

El análisis de este mecanismo de "áreas reservadas" resulta de particular importancia dado que, al origen de la solicitud de opinión consultiva, se encuentran dos solicitudes para la aprobación de planes de trabajo en sitios de este tipo.

El 31 de marzo de 2008, el secretario general de la Autoridad Internacional de Fondos Marinos recibió notificación formal por parte de dos compañías, de su intención de presentar para aprobación un plan de trabajo para la exploración de nódulo polimetálicos en las "áreas reservadas". Las compañías son: la Nauru Ocean Resources Inc., compañía constituida en Nauru, y la Tonga Offshore Mining Ltd., compañía constituida en Tonga; ambas subsidiarias de la compañía Canadiense Nutilus Minerals Inc.

Posteriormente, el 10 abril de 2008, la Autoridad recibió para su aprobación los planes de trabajo de ambas compañías, patrocinados respectivamente por la República de Nauru y el Reino de Tonga. En el caso específico de Nauru Ocean Resources Inc., la solicitud cubre un área total de $74,830 \mathrm{Km}^{2}$ en la Zona Clarion-Clipperton situada en el Océano Pacífico.

De conformidad con la Convención y el Reglamento de nódulos, los planes de trabajo fueron transmitidos a la Comisión Jurídica y Técnica

$32 \S 5$, Sección 2, Anexo, Acuerdo de 1994.

33 Artículo 16, Reglamento de nódulos. Es necesario señalar que el Acuerdo de 1994 también estableció que hasta que la Empresa comience a operar independientemente de la Secretaría, esta última desempeñará las funciones de la Empresa, y sus actividades iniciales de explotación minera de los fondos marinos se llevarán a cabo por medio de empresas conjuntas. Véanse § 1 y 2, Sección 2, Anexo, Acuerdo de 1994. 
de la Autoridad a fin de que fueran examinados durante el 14o. Periodo de Sesiones de la Autoridad ese mismo año. La Comisión inició el examen de los planes de trabajo, pero señaló que "no había llegado a un consenso respecto de una recomendación al Consejo en relación con las solicitudes y, por tanto, continuaría el examen de las solicitudes en la próxima oportunidad posible" ${ }^{34} \mathrm{El}$ examen de estos planes de trabajo fue entonces incluido en la Agenda de la Comisión para el 15o. Periodo de Sesiones de la Autoridad en 2009. ${ }^{35}$

No obstante, el 5 de mayo de 2009, la Secretaría de la Autoridad Internacional de los Fondos Marinos fue informada por Nauru Ocean Resources Inc. y Tonga Offshore Mining Ltd. que, "en vista de las actuales circunstancias económicas mundiales y de otros problemas, habían decidido pedir que se aplazara el examen de su solicitud de aprobación de planes de trabajo para la exploración de nódulos polimétalicos". ${ }^{36}$ La Comisión tomó nota de la solicitud y decidió posponer hasta nuevo aviso el examen de los planes de trabajo. ${ }^{37}$

No existe información oficial alguna sobre "los otros problemas" a los que hicieron referencia ambas empresas al solicitar la postergación del examen de sus solicitudes; sin embargo, los hecho que se desarrollaron posteriormente permiten suponer la existencia de algunas divergencias en relación a la extensión de las obligaciones y responsabilidades de los Estados de Nauru y Tonga.

\section{B. La propuesta de Nauru para solicitar una opinión consultiva al Tribunal Internacional del Derecho del Mar}

Casi un año después de que las empresas solicitaron la postergación del examen de sus solicitudes, el 1o. de marzo de 2010, la República de

34 Véase § 7, "Declaración del Presidente del Consejo de la Autoridad Internacional de los Fondos Marinos sobre la labor del Consejo en el 14o. periodo de sesiones”, ISBA/14/C/11, del 5 de junio de 2008.

35 Véase $§ 23$, "Informe resumido del Presidente de la Comisión Jurídica y Técnica sobre la labor de la Comisión en el 16o. periodo de sesiones”, ISBA/16/C/7, del 28 de abril de 2010.

36 Véase "Nota de la Secretaría: Solicitudes de aprobación de planes de trabajo de exploración de Nauru Ocean Resources Inc. y Tonga Offshore Mining Ltd.”, ISBA/15/LTC/6, del 11 de mayo de 2009.

37 Véase § 23, "Informe resumido... cit., ISBA/16/C/7. 
Nauru transmitió al secretario general de la Autoridad Internacional de los Fondos Marinos una propuesta para solicitar una opinión consultiva del Tribunal Internacional del Derecho del Mar sobre varias cuestiones relativas a las obligaciones y responsabilidad de los Estados patrocinantes. $^{38}$

Según exponía Nauru, debido a una limitada capacidad financiera y tecnológica, los Estados en desarrollo se ven obligados a contratar entidades del sector privado a fin de poder participar eficazmente en las actividades en la Zona. Adicionalmente, estos Estados:

tampoco pueden exponerse a los riesgos jurídicos que puede acarrear un proyecto de esa índole. Habida cuenta de esas circunstancias, el patrocinio de Nauru Ocean Resources Inc. por Nauru se sustentó originalmente en el supuesto de que Nauru podría mitigar efectivamente (con un grado elevado de incertidumbre) las posibles responsabilidades o costos derivados de su patrocinio. Ello era importante pues esas responsabilidades o costos bien podrían, en alguna circunstancia, ser sobradamente superiores a las capacidades financieras de Nauru (así como también a las de muchos Estados en desarrollo). A diferencia de la minería en tierra, en la que un Estado por lo general solo arriesga perder aquello que ya posee (por ejemplo, su entorno natural), si se declarara que un Estado en desarrollo puede ser responsable por actividades en la Zona, el Estado bien podría perder mucho más de lo que en realidad posee. ${ }^{39}$

Nauru señaló que en conversaciones celebradas con el Secretariado de la Autoridad se sugirió que un Estado patrocinante podría cumplir sus obligaciones de patrocinio y evitar la responsabilidad si concertaba un contrato con un solicitante, con arreglo al cual:

a) Se facultará al Estado a inspeccionar y verificar el programa de trabajo del contratista y realizar un programa de auditoría ambiental;

38 La propuesta de Nauru fue circulada como parte de los documentos oficiales del 16o. periodo de sesiones de la Autoridad. Véase "Propuesta para solicitar una opinión consultiva a la Sala de Controversias de los Fondos Marinos del Tribunal Internacional del Derecho del Mar respecto de asuntos relativos a la responsabilidad de un Estado patrocinante: presentada por la delegación de Nauru”, ISBA/16/C/6 del 5 de marzo de 2010.

39 Ibidem, $§ 1$. 
b) El contratista se comprometiera a observar todas las condiciones y requisitos del Reglamento de la Autoridad y del contrato de exploración. ${ }^{40}$

No obstante, Nauru adujo que las "opiniones discrepantes entre los miembros de la Comisión Jurídica y Técnica en cuanto a la interpretación de las disposiciones de la Convención y del Acuerdo de 1994 relativo a la aplicación de la Parte XI de la Convención” hicieron patente la necesidad de "solicitar una aclaración respecto de esas disposiciones" antes de seguir adelante con el proyecto de patrocinio. ${ }^{41}$

Como resulta evidente de la propuesta de Nauru, sus inquietudes se referían, casi exclusivamente, a los riesgos pecuniarios que podrían derivarse del patrocinio de un proyecto de actividades en la Zona:

Sin claridad en cuanto a las cuestiones de responsabilidad, será sumamente difícil que un Estado en desarrollo pueda patrocinar con confianza actividades en la Zona, pues no se puede hacer un análisis válido de los riesgos jurídicos y posibles responsabilidades y sería imposible aplicar medidas de mitigación para evitar esa responsabilidad con algún grado de certidumbre. De resultas de ello, el Estado quedaría expuesto a una responsabilidad imprevista en derecho internacional.

En última instancia, si los Estados patrocinantes estuvieran expuestos a una responsabilidad que pudiera ser significativa, Nauru, así como otros Estados en desarrollo, podría verse privado de participar efectivamente en las actividades en la Zona, que es uno de los propósitos y principios de la Parte XI de la Convención, en particular conforme a lo dispuesto en el artículo 148, el párrafo c) del artículo 150 y el párrafo 2 del artículo 152. En consecuencia, a juicio de Nauru es esencial que se imparta orientación en cuanto a la interpretación de las disposiciones pertinentes de la Parte XI relativas a la responsabilidad, a fin de que los Estados en desarrollo puedan determinar si está dentro de sus capacidades mitigar eficaz-

40 Ibidem, $\$ 2$.

${ }^{41}$ Resulta necesario hacer referencia que el presidente de la Comisión Jurídica y Técnica señaló en su informe de las actividades llevadas a cabo durante el 16o. Periodo de Sesiones de la Autoridad que:

"La Comisión desea afirmar que estas "opiniones discrepantes" que se atribuyen a sus miembros no figuran en sus informes ni en ningún otro documento oficial. Además, se afirma correctamente que son los solicitantes quienes piden que el examen de sus solicitudes se aplace a causa de las actuales circunstancias económicas mundiales y otros problemas”.

Véase $§ 22$, "Informe resumido... cit., ISBA/16/C/7. 
mente esos riesgos y, a su vez, adoptar una decisión con conocimiento de causa respecto de si han o no de participar en las actividades en la Zona. ${ }^{42}$

Sobre la base de estas inquietudes, Nauru proponía solicitar al Tribunal la interpretación de prácticamente la totalidad de las disposiciones de la Parte XI de la Convención.

No obstante, un elemento de los cuestionamientos propuestos por Nauru que amerita particular atención se refiere a la posible existencia de diferencias en los parámetros aplicables para considerar satisfechos los estándares de responsabilidades y obligaciones de los Estados patrocinantes, cuando éstos sean Estados en desarrollo. Podemos encontrar los elementos de este cuestionamiento en varias partes de la propuesta de Nauru:

Como se ha destacado en la presente propuesta, el contrato de patrocinio (como todas las demás medidas) no constituirá una garantía absoluta de que el contratista dé cumplimiento a la Parte XI de la Convención. Por lo tanto, es preciso determinar si el contrato de patrocinio será suficiente para demostrar que el Estado ha adoptado todas las medidas necesarias y apropiadas para lograr el cumplimiento efectivo por parte del contratista. Con todo, como se demuestra en la presente propuesta, ello plantea su propia serie de interrogantes, entre los cuales ninguno más apremiante que el relativo a saber si el estándar de las medidas que se exigen a un Estado en desarrollo es diferente del exigido a un Estado desarrollado.

En cuanto a esa cuestión, si bien el contrato de patrocinio es eficaz en cuanto atribuye al Estado numerosos derechos y facultades para supervisar, verificar y regular las actividades del contratista, en realidad distintos Estados tendrán capacidades muy dispares para aplicar esas facultades y esa regulación. Esto es, si bien se harán esfuerzos en el marco del contrato de patrocinio para ayudar al Estado en desarrollo a cumplir sus responsabilidades (por ejemplo, se brindará asistencia financiera y técnica al Estado y, si el Estado careciera de capacidad para supervisar efectivamente las actividades, el contratista deberá contratar personal independiente con competencias apropiadas en materia de seguridad y medio ambiente para efectuar la supervisión en nombre del Estado), desafortunadamente es imposible que los Estados en desarrollo cumplan sus responsabilidades conforme al mismo estándar

42 Ibidem, $§ 4$ y 5. 
o en la misma escala que los Estados desarrollados, en particular cuando se trata de la reglamentación de la minería en los fondos marinos. Por ejemplo, el entorno del fondo marino es una esfera altamente especializada, y es de presumir que los Estados en desarrollo (en particular los Estados sin litoral) carecerán de competencias, capacitación y capacidad, por ejemplo, para verificar si existe la probabilidad de que las actividades mineras causen incidentes graves de contaminación o daño al medio ambiente.

Además, en cuanto a las medidas preventivas, el contrato de patrocinio dispone que el Estado debe haber comprobado de que se hayan cumplido ciertas condiciones antes de aprobar el inicio de las actividades. Si bien pone en manos del Estado un medio importante para ayudar a promover el cumplimiento, en realidad impone al Estado la carga de determinar si se han cumplido ciertas condiciones, circunstancia que plantea este interrogante: ipuede el Estado en desarrollo formar su propio juicio basado en sus capacidades para determinar si las condiciones se han cumplido o si existe un estándar mínimo de diligencia que se exige a todos los Estados? ${ }^{33}$

El argumento que Nauru presentó puede resumirse como sigue:

- Las limitantes de carácter técnico y financiero obligan a los Estados en desarrollo a celebrar contratos con entidades privadas a las que patrocinan ante la Autoridad Internacional de los Fondos Marinos. La Convemar establece que el patrocinio de personas privadas para llevar actividades en la Zona conlleva una serie de obligaciones y responsabilidades para los Estados patrocinantes.

- Habida cuenta de que un Estado en desarrollo puede no estar en condiciones de fiscalizar las actividades mineras en el lecho marino o hacer cumplir la legislación relativa a esas actividades con el mismo grado de efectividad que un Estado desarrollado, "cabe preguntarse si ¿el estándar de las medidas requeridas a los Estados en desarrollo es distinto del de las medidas requeridas a los Estados desarrollados?". ${ }^{44}$

- Esto es debido a que "es imposible que los Estados en desarrollo cumplan sus responsabilidades conforme al mismo estándar o en la

43 Ibidem, § 17-19.

${ }_{44} \S 7$ (b)(iv), "Propuesta para solicitar... cit., ISBA/16/C/6. 
misma escala que los Estados desarrollados, en particular cuando se trata de la reglamentación de la minería en los fondos marinos". ${ }^{45}$

- Por lo que la cuestión es determinar si “¿pueden esas disposiciones relativas a la responsabilidad del Estado patrocinante interpretarse de modo tal de que se promueva una participación efectiva de los Estados en desarrollo?”. ${ }^{46}$ A saber, a través de la determinación de "un límite al grado de la responsabilidad que puede enfrentar un Estado en desarrollo", en particular, tomando "en cuenta en la escala de responsabilidad la capacidad financiera del Estado en desarrollo". ${ }^{47}$

- De lo contrario, si existiera la posibilidad de que un Estado en desarrollo patrocinante pudiera quedar "expuesto a una responsabilidad imprevista en derecho internacional”, responsabilidad "que pudiera ser significativa”, los Estados en desarrollo se verían así privados de participar efectivamente en las actividades en la Zona. ${ }^{48}$

\section{La solicitud de opinión consultiva formulada por el Consejo de la Autoridad Internacional de los Fondos Marinos}

Durante el análisis de la propuesta de Nauru las opiniones de las delegaciones hicieron patente una falta de consenso al respecto. Mientras varios Estados manifestaron, en mayor o menor medida, su apoyo a la propuesta de solicitar una opinión consultiva, ${ }^{49}$ varios otros hicieron patente su oposición. ${ }^{50}$

45 Ibidem, $§ 18$.

46 Ibidem, $\S 7(\mathrm{~b})(\mathrm{v})$.

47 Ibidem, $§ 12$.

$48 \S 4$-5, "Propuesta para solicitar... cit., ISBA/16/C/6.

49 Tomando en cuenta la similitud entre los patrocinios de Nauru y Fiji, no resulta sorprendente que durante el análisis de la propuesta en el seno del Consejo de la Autoridad, la Delegación de Fiji haya apoyado ampliamente la propuesta de solicitud de opinión consultiva. Hablando a nombre del Grupo de Pequeños Estados Insulares en Desarrollo y Miembros de la Autoridad Internacional de los Fondos Marinos, la describió no como un intento de evasión de responsabilidades, sino como un llamado a la claridad y certitud sobre las obligaciones y responsabilidades de los Estados en desarrollo patrocinantes, lo que les permitiría participar en las actividades en la Zona a través del patrocinio de empresas privadas. Las delegaciones de México, Alemania, Corea, España, Trinidad y Tobago, Jamaica, Uganda, Sudán y Sudáfrica expresaron un apoyo más moderado a la propuesta, véase "Comunicado de Prensa", SB/16/12, 3 de mayo de 2010.

50 En este segundo grupo se situaron Países Bajos, Canadá, Reino Unido. Véase ibidem. 
Sobre la base de la solicitud de algunos Estados, y ante la anuencia de aquellos Estados que apoyaron la iniciativa sobre la necesidad de que las cuestiones que se plantearan al Tribunal fueran más claras y concisas, el Secretariado de la Autoridad presentó al Consejo un nuevo proyecto de decisión que acabó siendo, con cambios menores, el texto de las tres preguntas formuladas por el Consejo al Tribunal. ${ }^{51}$

Cabe resaltar que en la formulación preparada por el Secretariado y en aquélla adoptada por el Consejo se omitió una referencia explícita a la cuestión de la especificidad de los Estados en desarrollo, no obstante que, como muestran las declaraciones de esos Estados en el seno del Consejo de la Autoridad, esta cuestión se mantuvo como una de las principales razones de la solicitud. ${ }^{52}$

Finalmente, el 6 de mayo de 2010, el Consejo de la Autoridad decidió, de conformidad con el artículo 191 de la Convemar, ${ }^{53}$ solicitar a la Sala de Controversias de los Fondos Marinos del Tribunal Internacional del Derecho del Mar una opinión consultiva sobre tres cuestiones jurídicas relativas a las responsabilidades y obligaciones de los Estados patrocinantes de actividades en la Zona:

1. Cuáles son las responsabilidades y obligaciones jurídicas de los Estados partes en la Convención en cuanto al patrocinio de actividades en la Zona de conformidad con la Convención, en particular con la Parte XI, y con el Acuerdo de 1994 relativo a la aplicación de la Parte XI de la Convención de las Naciones Unidas sobre el Derecho del Mar, de 10 de diciembre de 1982;

2. Cuál es el grado de responsabilidad de un Estado parte en caso de que una entidad patrocinada por él en virtud del artículo 153, párrafo 2 b), de la Conven-

51 Un somero resumen de las discusiones tendientes a la adopción de este texto puede encontrarse en los Comunicados de prensa de la Autoridad; en particular SB/16/13 del 4 de mayo de 2010, y SB/16/18 y 19 del 6 de mayo de 2010 .

52 Por ejemplo, el delegado de Fiji urgió al Consejo a adoptar la decisión pues la opinión consultiva permitiría a los Estados en desarrollo a evaluar de forma más eficiente sus riesgos y responsabilidades derivados de estas actividades y patrocinar así a empresas privadas internacionales. Véase SB/16/18, cit.

53 El artículo 191 de la Convemar lee: "Cuando lo soliciten la Asamblea o el Consejo, la Sala de Controversias de los Fondos Marinos emitirá opiniones consultivas sobre las cuestiones jurídicas que se planteen dentro del ámbito de actividades de esos órganos. Esas opiniones se emitirán con carácter urgente”. 
ción incumpla las disposiciones de la Convención, en particular la Parte XI, y el Acuerdo de 1994;

3. Cuáles son las medidas necesarias y apropiadas que un Estado patrocinante debe tomar a fin de cumplir las responsabilidades que le incumben en virtud de la Convención, en particular del artículo 139 y el Anexo III, y del Acuerdo de $1994 .{ }^{54}$

2. Las responsabilidades y obligaciones derivadas de las actividades en la Zona y el trato especial y diferenciado para Estados en desarrollo previsto en la Convemar

La Parte XI y el Anexo III de la Convemar junto con el Acuerdo de 1994 establecen el marco jurídico para el desarrollo de actividades en la Zona; entendiéndose éstas como "todas las actividades de exploración y explotación de los recursos de la Zona”. ${ }^{55}$ Por su parte, los recursos de la Zona son definidos como "todos los recursos minerales sólidos, líquidos o gaseosos in situ en la Zona, situados en los fondos marinos o en su subsuelo, incluidos los nódulos polimetálicos". ${ }^{56}$

Este régimen jurídico convencional resulta particularmente complejo y constituye la razón principal por la cual la Convemar tardó tantos años en entrar en vigor. La negociación del Acuerdo de 1994 fue el resultado de un mandato expreso para, a través de esa negociación, buscar alcanzar una aceptación universal de la Convemar.

De conformidad con el artículo 2o. del Acuerdo de 1994, las disposiciones de ambos instrumentos, la Parte XI y el mismo Acuerdo, "deberán ser interpretadas y aplicadas en forma conjunta como un solo instrumento", y en caso de inconsistencia entre las disposiciones del Acuerdo de 1994 y la misma Parte XI de la Convención, las disposiciones del Acuerdo prevalecerán.

El sistema para la exploración y explotación de los recursos de la Zona está basado en el "sistema paralelo", que constituyó el acuerdo

54 "Decisión del Consejo de la Autoridad Internacional de los Fondos Marinos, en que se solicita una opinión consultiva con arreglo al artículo 191 de la Convención de las Naciones Unidas sobre el Derecho del Mar”, ISBA/16/C/13, del 6 de mayo de 2010.

55 Artículo 1(3), Convemar.

56 Artículo 133(b), Convemar. 
en paquete que reconcilió las divergencias que existían al respecto entre Estados en desarrollo y desarrollados. Como se examinó anteriormente, este sistema establece que la Zona puede ser explotada simultáneamente por la Empresa, y por Estados Parte a través de empresas estatales, personas naturales o jurídicas que posean la nacionalidad de ese Estado Parte o que sean efectivamente controladas por ellos o por sus nacionales, o por cualquier agrupación con operadores comerciales privados. ${ }^{57}$

Se dota de aplicabilidad práctica a las normas generales establecidos en la Convención y el Acuerdo de 1994 a través de normas, reglamentos y procedimientos que son desarrollados por los diferentes órganos de la Autoridad Internacional de los Fondos Marinos. Es por ello que el resultado de facto del Acuerdo de 1994 fue establecer una moratoria en la explotación de los minerales de la Zona.

Como se verá a continuación, el régimen jurídico del sistema paralelo de explotación de los recursos en la Zona establece obligaciones diferentes para los tres sujetos involucrados en estas actividades: i) la Autoridad, ii) los Estados, y iii) las empresas, privadas o estatales, patrocinadas por esos Estados. Es precisamente la definición de estas responsabilidades y obligaciones que constituye la litis de la opinión consultiva solicitada al Tribunal, y que por ende analizaremos en detalle.

\section{A. Las responsabilidades y obligaciones de los Estados patrocinantes derivadas de las actividades en la Zona}

La Convención establece que la Autoridad ejercerá sobre las actividades en la Zona "el control que sea necesario para lograr que se cumplan las disposiciones pertinentes"; mientras que los Estados Parte deberán prestarle asistencia "adoptando todas las medidas necesarias para lograr dicho cumplimiento". ${ }^{58}$

En este sentido, los Estados patrocinantes están obligados a velar por que las actividades en la Zona se efectúen de conformidad con lo establecido en la Convemar. Si bien la Convención es determinante en el

57 Artículo 153, Convemar. Véase el análisis que se hace de esta cuestión en la Sección 1(a) de este trabajo, pp. 6-8 supra.

58 Artículo 153(4), Convemar. 
sentido de que estos Estados serán “conjunta y solidariamente responsables" de "los daños causados por el incumplimiento" de sus obligaciones; también es inequívoca al establecer que "el Estado Parte no será responsable de los daños causados en caso de incumplimiento de esta Parte por una persona a la que haya patrocinado ... si ha tomado todas las medidas necesarias y apropiadas para lograr el cumplimiento efectivo ...". ${ }^{59}$

Los límites de la responsabilidad internacional de los Estados patrocinantes están desarrollados en el Anexo III de la Convemar, donde se establece que:

El Estado o los Estados patrocinantes estarán obligados, con arreglo al artículo 139, a procurar, en el marco de sus ordenamientos jurídicos, que los contratistas patrocinados por ellos realicen sus actividades en la Zona de conformidad con las cláusulas de sus contratos y con las obligaciones que les incumban en virtud de esta Convención. Sin embargo, un Estado patrocinante no responderá de los daños causados por el incumplimiento de sus obligaciones por un contratista a quien haya patrocinado si ha dictado leyes y reglamentos y adoptado medidas administrativas que, en el marco de su ordenamiento jurídico, sean razonablemente adecuados para asegurar el cumplimiento por las personas bajo su jurisdicción. ${ }^{60}$

En este sentido, es evidente que las responsabilidades y obligaciones de los Estados patrocinantes están estrechamente ligadas a aquéllas propias de la Autoridad y de los solicitantes que patrocinen. Es por ello que resulta necesario determinar el contenido las responsabilidades y obligaciones de estos últimos, a fin de estar en posibilidades de determinar el estándar de cumplimiento de las obligaciones de los Estados.

El Anexo III de la Convención, junto con las enmiendas introducidas por el Acuerdo de 1994, detallan las condiciones básicas, aplicables a todos los contratistas, para la prospección, exploración y explotación de los recursos de la Zona. El Anexo III de la Convención establece que la Autoridad adoptará y aplicará "Normas y prácticas de extracción de minerales, incluidas las referentes a la seguridad de las operaciones, la conservación de los recursos y la protección del medio marino". ${ }^{61}$

59 Artículo 139(1) y (2), Convemar.

60 Artículo 4.4, Anexo III, Convemar.

${ }^{61}$ Artículo $17 \S 1(\mathrm{~b})(x i i)$, Anexo III, Convemar. 
Por su parte, el Acuerdo de 1994 requiere que la Autoridad al adoptar las normas, reglamentos y procedimientos previstos en el artículo 162 de la Convemar, adopte también "normas, reglamentos y procedimientos en que se incorporen los estándares aplicables sobre protección y preservación del medio marino". ${ }^{62}$

A este respecto, es necesario señalar que si bien la Parte XII de la Convención establece a grandes rasgos las obligaciones de los Estados Parte en este ámbito, por el contrario la Parte XI, relativa a las actividades en la Zona, únicamente contiene un requerimiento general por el que se establece que "Se adoptarán con respecto a las actividades en la Zona las medidas necesarias de conformidad con esta Convención para asegurar la eficaz protección del medio marino contra los efectos nocivos que puedan resultar de esas actividades". ${ }^{63}$ En este sentido, y conforme a la Convemar, corresponde a la Autoridad establecer las "normas, reglamentos y procedimientos apropiados" para:

a) Prevenir, reducir y controlar la contaminación del medio marino y otros riesgos para éste, incluidas las costas, y la perturbación del equilibrio ecológico del medio marino, prestando especial atención a la necesidad de protección contra las consecuencias nocivas de actividades tales como la perforación, el dragado, la excavación, la evacuación de desechos, la construcción y el funcionamiento o mantenimiento de instalaciones, tuberías y otros dispositivos relacionados con tales actividades;

b) Proteger y conservar los recursos naturales de la Zona y prevenir daños a la flora y fauna marinas. ${ }^{64}$

Sobre esta base, el Reglamento de nódulos prevé, además de las condiciones para la prospección y la aprobación de un plan de trabajo para la exploración de nódulos polimetálicos, los principios de base y los procedimientos relativos a la protección y preservación del medio marino; aplicando el “criterio de precaución” y estableciendo que "el Contratista tomará las medidas necesarias para prevenir, reducir y controlar la contaminación del medio marino y otros riesgos para éste derivados

62 §5(f), Sección 1, Anexo, Acuerdo de 1994.

63 Artículo 145, Convemar.

${ }^{64}$ Idem. 
de sus actividades en la Zona en la medida en que sea razonablemente posible y utilizando la mejor tecnología de que disponga". ${ }^{65}$

Conforme establece el Reglamento de nódulos toda solicitud de aprobación de un plan de trabajo deberá incluir información "concreta y suficiente que permita al Consejo comprobar si el solicitante tiene la capacidad financiera y técnica para realizar el plan de trabajo para la exploración propuesta y para cumplir sus obligaciones financieras con la Autoridad". ${ }^{66}$

Adicionalmente, en su solicitud los solicitantes deberán incluir un compromiso escrito para:

a) Aceptar y cumplir las obligaciones aplicables que dimanen de las disposiciones de la Convención y las normas, los reglamentos y los procedimientos, de la Autoridad, las decisiones de los órganos competentes de la Autoridad y las cláusulas de los contratos celebrados con ella;

b) Aceptar el control de la Autoridad sobre las actividades en la Zona en la forma autorizada por la Convención; y

c) Dar a la Autoridad por escrito seguridades de que cumplirá de buena fe las obligaciones estipuladas en el contrato. ${ }^{67}$

El Reglamento de nódulos requiere igualmente que los solicitantes presenten datos e información tendientes a dar cumplimiento al requerimiento, contemplado en el Acuerdo de 1994, de proveer

una evaluación de los posibles efectos sobre el medio ambiente de las actividades propuestas y de una descripción de un programa de estudios oceanográficos y estudios de referencia sobre el medio ambiente de conformidad con las normas, reglamentos y procedimientos aprobados por la Autoridad. ${ }^{68}$

65 Artículo 31 (2) y (3), Parte V, Reglamento de nódulos. El estándar para el cumplimiento de esta obligación está determinado por las "Recommendations for the guidance of the contractors for the assessment of possible environmental impacts arising from exploration for polymetallic nodules in the Area" elaboradas por la Comisión Jurídico Técnica de la Autoridad Internacional de los Fondos Marinos en 2001. Véase ISBA/7/LTC/1/Rev. 1 y Corr. 1.

66 Artículo 12, Reglamento de nódulos.

67 Artículo 14, Reglamento de nódulos.

68 §7, Sección 1, Anexo, Acuerdo de 1994. Los datos e información que deberán presentar los solicitantes están enlistados en el artículo 18 del Reglamento de nódulos. 
El solicitante también deberá obtener "datos ambientales de referencia y el establecimiento de líneas de base ambientales" a fin de evaluar los efectos probables en el medio marino de su programa de actividades, así como un programa para vigilar esos efectos. Adicionalmente, "informará por escrito anualmente al Secretario General de la aplicación y los resultados del programa de vigilancia”. En caso de que el solicitante requiera derechos de explotación, “deberá proponer zonas que se utilicen exclusivamente como zonas de referencia para los efectos y para la preservación. ${ }^{69}$

El Reglamento establece un procedimiento para que el Consejo, en el ejercicio de las facultades, ${ }^{70}$ expida órdenes de emergencia con el objeto de prevenir, contener o reducir al mínimo los daños graves al medio marino derivados de actividades realizadas en la Zona. ${ }^{71}$

Finalmente, y en lo que refiere a las obligaciones y responsabilidad del solicitante y de la Autoridad, el Reglamento de nódulos sigue lo previsto en la Convención; ${ }^{72}$ a saber que "El Contratista seguirá siendo responsable de todos los daños y perjuicios derivados de los actos ilícitos cometidos en la realización de sus operaciones, en particular los daños al medio marino, después de finalizada la etapa de exploración". ${ }^{73}$

En conclusión, y derivado la doble obligación de los Estados patrocinantes de, por una parte, prestarle asistencia a la Autoridad a fin de que ésta ejerza sobre las actividades en la Zona "el control que sea necesario para lograr que se cumplan las disposiciones pertinentes", ${ }^{74} \mathrm{y}$ por el otro lado el de "procurar, en el marco de sus ordenamientos jurídicos, que los contratistas patrocinados por ellos realicen sus actividades en

${ }_{69}$ El Reglamento de nódulos establece que se entenderá por “Zonas de referencias para los efectos" las que se utilicen para evaluar los efectos en el medio marino de las actividades del contratista en la Zona y que sean representativas de las características ambientales de la Zona. Se entenderá por "Zonas de referencia para la preservación” aquéllas en que no se efectuarán extracciones a fin de que la biota del fondo marino se mantenga representativa y estable y permita evaluar los cambios que tengan lugar en la flora y la fauna del medio marino. Artículo 31(4, 5, 6 y 7), Parte V, Reglamento de nódulos.

70 Artículo 162(2)(w), Convemar.

71 Artículo 32, Reglamento de nódulos.

72 Véase artículo 139 de la Convención y artículo 22, Anexo III, Convemar.

73 Artículo 30, Reglamento de nódulos.

74 Artículo 153(4), Convemar. 
la Zona de conformidad con las cláusulas de sus contratos y con las obligaciones que les incumban en virtud de esta Convención", ${ }^{75}$ resulta entonces comprensible la inquietud manifestada por Nauru en cuanto a la extensión de sus obligaciones y de los parámetros aplicables para considerar satisfechos los estándares de responsabilidades y obligaciones de los Estados patrocinantes, en particular cuando éstos sean Estados en desarrollo.

Las inquietudes de Nauru y Tonga parecen aún más pertinentes al considerar que su patrocinio se refiere a actividades en áreas reservadas, lo que, como se ha señalado previamente, es una facultad exclusiva para los Estados en desarrollo. Como veremos a continuación, esta exclusividad constituye una parte esencial del principio de trato especial y diferenciado para Estados en desarrollo tal y como quedó reflejado en la Convemar.

\section{B. El principio de trato especial y diferenciado para Estados en desarrollo cristalizado en la Convemar}

Es posible encontrar evidencia del principio de trato especial y diferenciado para Estados en desarrollo en múltiples áreas del derecho internacional y en un importante número de instrumentos convencionales. Por ejemplo, es posible encontrar disposiciones que cristalizan este principio en el régimen jurídico de la Organización Mundial de Comercio, en varios instrumentos convencionales relativos a la protección ambiental y a la protección de derechos de propiedad intelectual, y obviamente en la Convención de Naciones Unidas sobre Derecho del Mar.

De un análisis sistémico de estas disposiciones, es también posible identificar ciertos tipos de trato especial y diferenciado para Estados en desarrollo que se prevén en la mayor parte de estos instrumentos convencionales, a saber: i) salvaguardar los intereses y necesidades de los Estados en desarrollo; ii) disposiciones que flexibilizan la regla general, por ejemplo a través del otorgamiento de mayores lapsos de tiempo, la posibilidad de excluir algunos sectores, o la posibilidad de hacer uso de algunas medidas generalmente prohibidas; iii) asistencia téc-

75 Artículo 4.4, Anexo III, Convemar. 
nica; iv) transferencia de tecnología, y v) algunos aspectos relativos a contribuciones financieras.

Como es obvio suponer, para el examen que se está llevando a cabo nos centraremos exclusivamente en las disposiciones de trato especial y diferenciado contempladas en la Convemar. ${ }^{76}$

Como se ha señalado previamente, la Convención de Naciones Unidas sobre el Derecho del Mar, tanto el texto adoptado en 1982 como las enmiendas introducidas por el Acuerdo de 1994, es el resultado de su tiempo y por ende presenta las características de la situación mundial de ese momento.

Si bien el texto adoptado en 1982 reflejaba en gran medida los intereses de los Estados en desarrollo, y fue el resultado de la predominancia de éstos en la escena internacional del momento; por el contrario el Acuerdo de 1994 refleja un cambio en el equilibrio de poder a nivel mundial, y enmienda la Parte XI de la Convemar de forma tal que los intereses de los Estados desarrollados, y en particular de Estados Unidos, quedaron mejor reflejados en el texto.

No obstante, y como su nombre lo indica, el Acuerdo de 1994 se refiere exclusivamente a las disposiciones contenidas en la Parte XI de la Convemar, relativa a la Zona y a las actividades en ella.

Como se verá a continuación, por una parte, el principio de trato especial y diferenciado para Estados en desarrollo que quedó cristalizado en el texto de la Convemar no está exclusivamente contenido en la Parte XI, y, por otra parte, las enmiendas introducidas a través del Acuerdo de 1994 no afectaron la totalidad de las disposiciones de este tipo contenidas en la parte XI.

Sobre esta base, resulta procedente, a fin de entender el cuestionamiento presentado por Nauru y Tonga, analizar someramente cómo fue cristalizado el principio de trato especial y diferenciado para Estados en desarrollo en la Convemar a fin de estar, posteriormente, en posibili-

76 Para un análisis minucioso del estatus del principio de trato especial y diferenciado para Estados en desarrollo en derecho internacional a través del examen de las deposiciones convencionales de estas áreas, véase Guerrero Peniche, J. Nicolás, The Principle of Special and Differential Treatment for Developing States in International Law: A Study of the Differences in Rights and Obligations Derived from Differences in Development, tesis de doctorado, Ginebra, Instituto de Estudios Internacionales y de Desarrollo, mayo de 2006. 
dad de determinar la procedencia o no del planteamiento de estos dos Estados.

Al examinar en detalle los artículos de la Convemar, resulta evidente la presencia de una considerable cantidad de disposiciones que incorporan en la norma las especificidades de los Estados en desarrollo. Las disposiciones en cuestión, si bien no lo mencionan explícitamente, sí establecen un trato especial y diferenciado para esos Estados.

Tal y como quedó cristalizado en las disposiciones de Convemar, el trato especial y diferenciado para Estados en desarrollo se refiere a cuatro diferentes temas: i) la salvaguarda de los intereses y necesidades de los Estados en desarrollo; ii) asistencia técnica; iii) transferencia de tecnología, y iv) algunos aspectos de contribuciones financieras. A fin de sistematizar el análisis, se realizará a continuación una presentación no exhaustiva de ejemplos de cada uno de estos cuatro tipos de trato especial y diferenciado.

a. Salvaguardar los intereses y necesidades

de los Estados en desarrollo

Este tipo de trato especial y diferenciado para Estados en desarrollo se traduce en términos prácticos en varias y diversas acciones a favor de esos Estados. A continuación se presentarán brevemente algunas de ellas a fin de ejemplificar someramente su contenido y evidenciar la especificidad del trato que prevén en función de las diferencia en los niveles de desarrollo de algunos de los Estados Parte de la Convención. Analizaremos en particular 3 ejemplos: i) tomar debidamente en consideración los intereses y necesidades de los Estado en desarrollo; ii) promoción de la participación de estos Estados en ciertas actividades; iii) búsqueda de una participación representativa de los Estados en desarrollo en los órganos de toma de decisiones.

La referencia a la necesidad de tomar en consideración los intereses y necesidades específicas de los Estados en desarrollo está presente desde el preámbulo de la Convemar. El quinto párrafo preambular hace referencia expresa en los siguientes términos: 
Teniendo presente que el logro de esos objetivos contribuirá a la realización de un orden económico internacional justo y equitativo que tenga en cuenta los intereses y necesidades de toda la humanidad y, en particular, los intereses y necesidades especiales de los países en desarrollo, sean ribereños o sin litoral. ${ }^{77}$

Se encuentra una referencia similar en lo relativo a las acciones de la Autoridad Internacional de los Fondos Marinos. Si bien se establece claramente que deberá evitar "toda discriminación en el ejercicio de sus facultades y funciones", no obstante, se prevé explícitamente que "podrá prestar atención especial a los Estados en desarrollo, en particular a aquéllos sin litoral o en situación geográfica desventajosa...". ${ }^{78}$

Resulta entonces procedente examinar el contenido de esta disposición y el parámetro que se establece a fin de dar cumplimiento a lo ahí dispuesto. A primera vista puede no resultar evidente qué se requiere de la Autoridad y cuál es el parámetro aplicable para considerar satisfecha esta disposición; no obstante, los trabajos preparatorios que llevaron a la codificación de este artículo brindan algunos elementos interesantes.

77 El origen de este párrafo es una propuesta de México en la que se hacía referencia al Nuevo Orden Económico Internacional: “Convinced also that the establishment of just and equitable conditions for the use of the sea and its resources will contribute to the development of the new international economic order". Véase "Mexico: draft preambular paragraphs", 5 May 1978, A/CONF.62 /L.24. Reproducido en Platzöder, R., Third United Nations Conference on the Law of the Sea, vol. XV, p. 8. Adicionalmente, es necesario señalar que el representante de México, el señor Gómez Robledo, al presentar su propuesta señaló que este párrafo era "particularmente importante pues establecía una conexión entre la Convención y el nuevo orden económico internacional". Véase "Summary records of $96^{\text {th }}$ Plenary meeting”, Third UN Conference on the Law of the Sea: Official Records, vol. IX, UN, NY, 1980, p. 34. La propuesta mexicana fue complementada por otra del Grupo de los 77, que la reforzó al incluir la referencia a las resoluciones de la Asamblea General de la ONU y "salvaguardando los intereses y necesidades especiales de los países en desarrollo". Véase "Draft text of preamble proposed by Fiji on behalf of the Group of 77”, 13 de octubre de 1978, A/CONF.62/L.33. Reproducido en Platzöder, R., Third United Nations Conference on the Law of the Sea, vol. XV, p. 15. El párrafo fue posteriormente modificado por el presidente de la Plenaria en aras de evitar declaraciones controversiales y polémicas en el preámbulo. Véase Nordquist, M. H. (ed. en jefe), "Preamble", United Nations Convention on the Law of the Sea, 1982: A Commentary, vol. I, 2002, Martinus Nijhoff, La Haya, p. 458.

78 Artículo 152, Convemar. Para un análisis minucioso del contenido de este párrafo preambular de la Convemar, véase Guerrero Peniche, J. Nicolás, "The Principle of Special and Differential Treatment for Developing States in International Law...”, cit. 
El Grupo de Trabajo I del Sub-Comité I preparó, en 1972, un documento en el que se explicitaba el contenido de la noción de "prestar atención" a través de una serie de medidas concretas que la Autoridad debería tomar a fin de "tomar debidamente en consideración el propósito primordial de promover el desarrollo de los países en desarrollo”:

notamment en a) évitant les éventuelles répercussions défavorables de l'exploitation, aux fins de cet avancement, d'une partie quelconque de la Zone ou en versant, le cas échéant, une indemnité en dédommagement de ces répercussions, b) en affectant une part approprié de ses recettes à cet avancement et c) en encourageant la participation des pays en voie de développement dans les activités menées par elle ou en son nom. ${ }^{79}$

Parecería entonces que esta disposición establece acciones concretas que la Autoridad deberá llevar a cabo: evitar las repercusiones negativas para los Estados en desarrollo, o en su defecto otorgarles indemnización o compensación; reservar una parte de sus beneficios y promover la participación de estos Estados en las actividades en la Zona.

El artículo 148 de la Convemar contiene otra referencia similar a la promoción de "la participación efectiva de los Estados en desarrollo en las actividades en la Zona, según se dispone expresamente en esta Parte, teniendo debidamente en cuenta sus intereses y necesidades especiales". ${ }^{80}$

Adicionalmente, es posible encontrar disposiciones de la Convemar por las que se busca garantizar una representación adecuada de los Estados en desarrollo en los diferentes órganos creados por la Convención misma. Este esfuerzo toma la forma de dos métodos diferentes: a través de la asignación de un número mínimo de los puestos disponibles, o a

79 El documento fue reproducido en el Informe de 1972 del Comité para el Fondo Marino: "Rapport du Comité des Utilisations Pacfiques du Fond des Mers et des Océans au-delà des Limites de la Juridiction Nationale”, 27 GAOR (1972), Supplément No. 21, A/8721, p. 106.

${ }_{80}$ No obstante, es necesario señalar que parte de la doctrina estima que esta disposición es meramente declarativo y que no establece ninguna obligación más allá de las contenidas en la misma Parte XI de la Convención. Véase Nandan, S. N., Lodge, M. W., and Rosenne, S. (eds.), vol. VI, 1982: A Commentary, Nordquist, Myron H. (ed. in chief), 2002, La Haya, Martinus Nijhoff, p. 224. 
través de "una representación razonablemente proporcional a su representación” en el órgano en particular.

Un ejemplo del primer método lo constituyen los dos asientos reservados a los Estados en desarrollo en la compleja fórmula para la distribución de puestos para la conformación del Consejo de la Autoridad Internacional de los Fondos Marinos. ${ }^{81}$ Adicionalmente, la Convemar establece que al elegir a los miembros del Consejo, la Asamblea de la Autoridad velará porque dos subgrupos de Estados en desarrollo "tengan una representación razonablemente proporcional” a su número en función del total de los Estados Parte de la Convención. ${ }^{82}$

\section{b. Asistencia técnica}

La asistencia técnica para los Estados en desarrollo constituye uno de los mecanismos más comúnmente utilizados del trato especial y diferenciado para Estados en desarrollo. En el ámbito de la Convemar se prevé el otorgamiento de asistencia técnica en lo relativo a dos cuestiones: la protección del medio marino y para la investigación científica marina.

En el caso del otorgamiento de asistencia técnica en materia de protección del medio marino, el artículo 202 de la Convemar establece una obligación general para los Estados Parte de Convemar a fin de que "actuando directamente o por conducto de las organizaciones internacionales competentes" promuevan "programas de asistencia científica, educativa, técnica y de otra índole a los Estados en desarrollo para la protección y preservación del medio marino y la prevención, reducción y control de la contaminación marina”. ${ }^{83}$ Adicionalmente, el artículo 203 busca prevenir, reducir y controlar la contaminación del medio marino o reducir lo más posible sus efectos, para lo cual establece que "los

81 En realidad las disposiciones correspondientes del Acuerdo de 1994 que enmendaron el Artículo 161(1) de la Convemar reservan "por lo menos dos [puestos para] Estados en desarrollo cuyas exportaciones de esos minerales tengan importancia considerable para su economía”, §15(c), Sección 3, Anexo, Acuerdo de 1994.

82 Los dos subgrupos a los que se hace referencia son "Los Estados sin litoral o en situación geográfica desventajosa” y "Los Estados ribereños, especialmente los Estados en desarrollo, en que no concurran las condiciones señaladas en los apartados a), b), c) o d) del párrafo 1”, véase artículo 161(2)(a) y (b), Convemar.

83 Artículo 202(a), Convemar. 
Estados en desarrollo recibirán de las organizaciones internacionales un trato preferencial" en la "asignación de fondos y asistencia técnica apropiados" y en la "utilización de sus servicios especializados".

No obstante, es necesario señalar que si bien estas dos disposiciones constituyen un reconocimiento de la necesidad de asistencia que requieren los Estados en desarrollo a fin de dar cumplimiento a sus obligaciones en materia de protección del medio marino, no "afectan la responsabilidad general de los Estados en desarrollo de dar cumplimiento" a sus obligaciones en esta materia. ${ }^{84}$

En cuanto a asistencia técnica para la investigación científica marina se refiere, la Convemar establece que:

Los Estados y las organizaciones internacionales competentes facilitarán, de conformidad con esta Convención, mediante su publicación y difusión por los conductos adecuados, información sobre los principales programas propuestos y sus objetivos, al igual que sobre los conocimientos resultantes de la investigación científica marina ${ }^{85}$

El contenido de esta disposición y las acciones requeridas para su cumplimiento fueron posteriormente desarrollados por la Comisión Oceanográfica Intergubernamental de la Organización de las Naciones Unidas para la Educación la Ciencia y la Cultura (Unesco/COI) ${ }^{86}$ y por la Asamblea General de la ONU. ${ }^{87}$

${ }^{84}$ Rosenne, S. y Yankov, A. (eds.), op. cit., pp. 99, 107. Para un análisis detallado del contenido de estas disposiciones véase Guerrero Peniche, J. Nicolás, "The Principle of Special and Differential Treatment for Developing States in International Law...”, cit.

85 Artículo 244(2), Convemar.

86 En 1985 la Organización de las Naciones Unidas para la Educación, la Ciencia y la Cultura adoptó el "UNESCO/IOC Comprehensive Plan for Major Assistance Programme to Enhance the Marine Science Capabilities of Developing Countries”, 4 de enero de 1985, UNESCO SC-85/WS/1, IOC/INF-612. Reproducido en Yearbook of the Netherlands Institute for the Law of the Sea, vol. 1, 1985, pp. 616-629.

87 En 2003, la Asamblea General de la ONU enumeró algunas actividades concretas a fin de otorgar asistencia técnica a los Estados en desarrollo en material de investigación científica marina: "Calls upon States and international financial institutions, including through bilateral, regional and international cooperation programmes and technical partnerships, to continue to strengthen capacity-building activities, in particular in developing countries, in the field of marine scientific research by, inter alia, training the necessary skilled personnel, providing 
c. Transferencia de tecnología

La Convemar presenta una considerable variedad de disposiciones relativas a la transferencia de tecnología a favor de los Estados en desarrollo. Es posible explicar esta diversidad tomando en consideración las diferencias en el nivel de cooperación previsto, los intereses económicos involucrados y la relevancia económica y oportunidades de mercado de la tecnología en cuestión. ${ }^{88}$ Sobre esta base, se pueden identificar disposiciones relativas a la transferencia de varios tipos de tecnología: para pesca, en relación a las actividades en la Zona, y para la protección y preservación del medio marino. Adicionalmente existen disposiciones relativas a la transferencia de tecnología en general.

Tomando en consideración que éste no es el tema central del análisis que se está desarrollando, nos referiremos únicamente en las disposiciones generales de transferencia de tecnología. ${ }^{89}$

La Parte XIV de la Convemar, compuesta por 13 artículos (266 a 278), establece el marco jurídico para la transferencia de tecnología en general, y ha sido reconocida como "a comprehensive system to advance technology, technological capabilities and technological interchange on a global level by a system of institutionalized state cooperation". ${ }^{90}$

Si bien los artículos de la Parte XIV de Convemar establecen una obligación para los Estados Parte de cooperar entre sí y con los organismos internacionales a fin de promover, facilitar y estimular el acceso a el desarrollo de transferencia de tecnología marina, ${ }^{91}$ también es cierto que estas disposiciones podrían haberse visto beneficiadas de una for-

the necessary equipment, facilities and vessels, and transferring environmentally sound technologies". §37, "Resolución sobre los Océanos y Derecho del Mar”, 21 de febrero de 2003, A/RES/57/141.

88 Stoll, P.-T.; "The Entry into Force of the Convention on the Law of the Sea: A Redistribution of Competences in Relation to the Management of the International Commons?", Zeitschrift für auslädisches öffentiliches Recht undVölkerrecht, vol. 55, núm. 2, 1995, p. 398.

89 El lector ávido de un análisis detallado de las disposiciones relativas a las otras áreas podrá referirse a Guerrero Peniche, J. Nicolás, "The Principle of Special and Differential Treatment for Developing States...", op. cit.

90 Stoll, P.-T., "The Entry into Force of the Convention...”, cit., p. 397.

${ }_{91}$ Pinto, M.C.W., "Transfer of Technology under the UN Convention of the Law of the Sea”, Ocean Yearbook, vol. 6, 1986, p. 265. 
mulación menos laxa. No obstante, resulta innegable que constituyen prueba de la intención de los Estados Parte de la Convemar por reconocer las especificidades de los Estados en desarrollo. ${ }^{92}$

Por ejemplo, el artículo 266 de Convemar establece que los Estados deberán cooperar para fomentar activamente el desarrollo y la transmisión de la ciencia y la tecnología marinas según modalidades y condiciones equitativas y razonables; fomentando

el desarrollo de la capacidad de los Estados que necesiten y soliciten asistencia técnica en esa esfera, particularmente de los Estados en desarrollo ... en lo referente a la exploración, explotación, conservación y administración de los recursos marinos, la protección y preservación del medio marino, la investigación científica marina y otras actividades en el medio marino compatibles con esta Convención, con miras a acelerar el desarrollo económico y social de los Estados en desarrollo.

Para ello, los Estados procurarán promover “condiciones económicas y jurídicas favorables para la transmisión de tecnología marina, sobre una base equitativa, en beneficio de todas las partes interesadas.”

Adicionalmente, los Estados también deberán fomentar:

92 Algunos autores son muy críticos respecto al valor jurídico de estas disposiciones, señalando que "these provisions do not lay down clear legal obligations but only establish certain standards of conduct which to a large extent reflect the already existing practice ... [and] are not likely to have any immediate discernible legal effect upon the transfer of marine technology”. Véase Boczek, B. A., The Transfer of Marine Technology to Developing Nations in International Law, Col. Occasional Paper núm. 32, 1982, The Law of the Sea Institute-University of Hawaii, Honolulú, pp. 33 y 34. No obstante, la mayoría de la doctrina no parece compartir esta evaluación tan negativa; por ejemplo Buhl, J. F., "Development and Transfer of Marine Technology", en Dupuy, R.-J. y Vignes, D. (eds.), A Handbook on the New Law of the Sea, vol. 1, 1991, Martinus Nijhoff-Hague Academy of International Law, Dordrecht, p. 1148; Pinto, M.C.W., "Transfer of Technology under the UN Convention...”, cit. p. 265; Rosenne, S. y Yankov, A. (eds.), op. cit., pp. 668, y Yankov, A., "The Significance of the 1982 Convention of the Law of the Sea for the Protection of the Marine Environment an the Promotion of Marine Science and Technology: A Paper on Third Committee Issues”, en Koers, A. W. and Oxman, B. H. (eds.), The 1982 Convention on the Law of the Sea: Law of the Sea Institute $17^{\text {th }}$ Annual Conference, The Law of the Sea Institute, Honolulu, 1984, pp. 93 y 94. 
a) La adquisición, evaluación y difusión de conocimientos de tecnología marina y facilitarán el acceso a esos datos e informaciones; b) El desarrollo de tecnología marina apropiada; c) El desarrollo de la infraestructura tecnológica necesaria para facilitar la transmisión de tecnología marina; d) El desarrollo de los recursos humanos mediante la capacitación y la enseñanza de nacionales de los Estados y países en desarrollo y especialmente de los menos adelantados entre ellos; e) La cooperación internacional en todos los planos, especialmente en los planos regional, subregional y bilateral. ${ }^{93}$

Resulta conveniente señalar que la obligación de transferencia de tecnología contenida en la Convemar parece establecer un sistema "gradual" en donde en la medida en que las necesidades de asistencia técnica y transferencia de tecnología de los Estados se reduzcan, se incrementaría proporcionalmente su obligación de promover a su vez los programas de los que se beneficiaron. ${ }^{94}$

\section{d. Contribuciones financieras}

La Convemar también contiene varias disposiciones por las que se cristalizó el trato especial y diferenciado para Estados en desarrollo en materia de contribuciones financieras. Uno de los ejemplos más claros se encuentra contemplado en el artículo 82 que establece como regla general que los Estados ribereños que exploten los recursos no vivos de la plataforma continental más allá de las 200 millas marinas deberán efectuar anualmente "pagos o contribuciones en especie" respecto de toda la producción del sitio minero en cuestión. No obstante, se exenta de este pago a todo Estado en desarrollo que sea "importador neto de un recurso mineral producido en su plataforma continental”.

Adicionalmente, la Convemar establece que estos pagos y contribuciones se distribuirán "entre los Estados Partes en esta Convención so-

93 Artículo 268, Convemar.

94 Uno de los esfuerzos más importantes a fin de facilitar la aplicación de las disposiciones relativas a la transferencia de tecnología y la investigación científica marina son las Directrices adoptadas en el seno de la COI/UNESCO. Para un análisis detallado del funcionamiento de este sistema de "graduación" en el otorgamiento del trato especial y diferenciado para Estados en desarrollo referirse a Guerrero Peniche, J. Nicolás, “The Principle of Special and Differential Treatment for Developing States...”, cit. 
bre la base de criterios de distribución equitativa, teniendo en cuenta los intereses y necesidades de los Estados en desarrollo, entre ellos especialmente los menos adelantados y los que no tienen litoral”.

Si bien estas disposiciones constituyen parte del desarrollo progresivo cristalizado por la Convemar, ${ }^{95}$ se ha argumentado que constituyen la única compensación para los estados sin litoral y los menos avanzados por la explotación de los recursos mineros por los Estados ribereños, ${ }^{96}$ y por ende el reconocimiento de su derecho a llevar a cabo estas actividades. ${ }^{97}$

Otro ejemplo de este tipo de trato especial y diferenciado para Estados en desarrollo lo constituye el establecimiento del "sistema de compensación” en favor de los países en desarrollo "cuyos ingresos de exportación o cuya economía sufran serios perjuicios como consecuencia de una disminución del precio o del volumen exportado de un mineral, en la medida en que tal disminución se deba a actividades en la Zona". ${ }^{98}$ Este sistema de compensación se vio menguado por la enmiendas introducidas por el Acuerdo de 1994, transformándolo en el establecimiento de "un fondo de asistencia económica" con cargo a aquella parte de los fondos de la Autoridad, procedentes exclusivamente de los pagos recibidos de los contratistas, que exceda los necesarios para cubrir los gastos administrativos de ésta, y cuya cantidad será determinada periódicamente por el Consejo. ${ }^{99}$

Del análisis precedente de las disposiciones de trato especial y diferenciado para Estados en desarrollo cristalizadas en Convemar, resulta un tanto más claro la búsqueda que Nauru inició a fin de esclarecer la extensión de sus responsabilidades y obligaciones como Estado patrocinante de actividades en la Zona.

95 Véase §101, Opinión disidente, Juez Oda, ICJ Reports 1982, p. 218.

96 Kwiatkowska, Barbara, The 200 Mile Exclusive Economic zone in the New Law of the Sea, Dordrecht, Martinus Nijhoff, 1989, p. 104.

97 Brown, E. D., Sea-Bed Energy and Minerals:The International Legal Regime, vol. 1, The Continental Shelf, La Haya, Martihus Nijhoff, 1992,pp. 369 y 370.

98 Artículo 151(10), Convemar.

99 Por ejemplo, Vignes considera que el establecimiento del Fondo convirtió al sistema en un mecanismo de caso por caso. Vignes, D., "La fin du schisme des fonds marins: A propos de la réunion de l'Assemblée générale des Nations Unies en session extraordinaire des 27, 28 et 29 juillet 1994 relative à la Convention sur le Droit de la Mer", Revue Belge de Droit International, vol. XXVIII, 1995-1, p. 157. 
No obstante, si bien esta prerrogativa de patrocinar actividades en áreas reservadas hace parte integral del trato especial y diferenciado para Estados en desarrollo contemplado en Convemar, considerar que por esa razón las obligaciones derivadas de un tal patrocinio resultarían inaplicables es una consideración difícil de sustanciar. Como veremos a continuación, la Sala de Controversias de los Fondos Marinos del Tribunal Internacional del Derecho del Mar parece haber seguido este mismo razonamiento.

\section{LA OPINIÓN CONSULTIVA DE LA SALA DE CONTROVERSIAS DE LOS FONDOS MARINOS DEL TRIBUNAL INTERNACIONAL DEL DERECHO DEL MAR}

ElTribunal Internacional del Derecho del Mar es una de las tres organizaciones establecidas por la Convemar. ${ }^{100}$ Constituye, junto con la Corte Internacional de Justicia y los tribunales arbitrales, ${ }^{101}$ uno de los tres mecanismos previstos para la solución de "toda controversia relativa a la interpretación o la aplicación de esta Convención”. ${ }^{102}$

Adicionalmente, la Convemar también prevé la constitución de una Sala de Controversias de los Fondos Marinos, ${ }^{103}$ cuyo ámbito de com-

100 Junto con la Comisión de Límites de la Plataforma Continental y la Autoridad Internacional de los Fondos Marinos.

101 No obstante, es necesario recordar que el artículo 280 de la Convemar establece que los Estados Partes podrán "convenir, en cualquier momento, en solucionar sus controversias relativas a la interpretación o la aplicación de esta Convención por cualquier medio pacífico de su elección". Adicionalmente, el artículo 282 de la Convención establece que "Cuando los Estados Partes que sean partes en una controversia relativa a la interpretación o la aplicación de esta Convención hayan convenido, en virtud de un acuerdo general, regional o bilateral o de alguna otra manera, en que esa controversia se someta, a petición de cualquiera de las partes en ella, a un procedimiento conducente a una decisión obligatoria, dicho procedimiento se aplicará en lugar de los previstos en esta Parte, a menos que las partes en la controversia convengan en otra cosa”.

102 Artículo 286, Convemar. Resulta procedente señalar que el artículo 287 de la Convención prevé que "Al firmar o ratificar esta Convención o al adherirse a ella, o en cualquier momento ulterior, los Estados podrán elegir libremente, mediante una declaración escrita, uno o varios" de los mecanismos enumerados para la solución de las controversias relativas a la interpretación o la aplicación de la Convención.

\footnotetext{
103 Artículo 186, Convemar.
} 
petencia comprende 5 categorías de controversias con respecto a actividades en la Zona. ${ }^{104}$ Por su parte, el artículo 191 de la Convención establece que "Cuando lo soliciten la Asamblea o el Consejo, la Sala de Controversias de los Fondos Marinos emitirá opiniones consultivas sobre las cuestiones jurídicas que se planteen dentro del ámbito de actividades de esos órganos”.

El Reglamento del Tribunal establece que el procedimiento consultivo sigue aquel del contencioso, por lo que consta de dos fases: una escrita y una oral. La primera consiste en la entrega de memorias y contra memorias y, si el Tribunal así lo autoriza, de una réplica y una dúplica; mientras que la oral consiste en la audiencia por el Tribunal de los agentes, abogados, consejeros, testigos y peritos. ${ }^{105}$

Por su parte, el Estatuto del Tribunal dispone que la Sala de Controversias de los Fondos Marinos estará integrada por 11 miembros designados por la mayoría de los miembros elegidos del Tribunal de entre ellos; asegurando la "representación de los principales sistemas jurídicos del mundo, así como una distribución geográfica equitativa”. ${ }^{106}$

104 Las 5 categorías de controversias con respecto a actividades en la Zona son: a) Las controversias entre Estados Partes relativas a la interpretación o aplicación de la Parte XI y de los anexos que a ella se refieren; b) ciertas controversias entre un Estado Parte y la Autoridad; c) las controversias entre partes contratantes, cuando éstas sean Estados Partes, la Autoridad o la Empresa, las empresas estatales y las personas naturales o jurídicas que se refieran a la interpretación o aplicación del contrato pertinente o de un plan de trabajo; o a los actos u omisiones de una parte contratante relacionados con las actividades en la Zona que afecten a la otra parte o menoscaben directamente sus intereses legítimos; d) las controversias entre la Autoridad y un probable contratista que haya sido patrocinado por un Estado y que haya cumplido las condiciones en relación con la denegación de un contrato o con una cuestión jurídica que se suscite en la negociación del contrato; e) las controversias entre la Autoridad y un Estado Parte, una empresa estatal o una persona natural o jurídica patrocinada por un Estado Parte cuando se alegue que la Autoridad ha incurrido en responsabilidad de conformidad con el artículo 22 del Anexo III, y f) las demás controversias para las que la competencia de la Sala se establezca expresamente en la Convención. Artículo 187, Convemar.

105 Artículo 44, "Reglamento del Tribunal Internacional para el Derecho del Mar", adoptado el 28 octubre de 1997 y enmendado el 15 de marzo y el 21 de septiembre de 2001, y el 17 de marzo de 2009, ITLOS/ 8 .

106 Artículo 35 “Estatuto del Tribunal Internacional de Derecho del Mar”, Anexo VI, Convemar. La Sala que emitió la Opinión estuvo compuesta por los siguientes miembros: Tullio Treves (presidente), Vicente Marotta Rangel, L. Dolliver M. Nelson, P. Chandrasekhara Rao, Rüdiger Wolfrum, Shunji Yanai, James L. Kateka, Albert J. Hoffmann, Zhiguo Gao, Boualem Bouguetaia, y Vladimir Vladimirovich Golitsyn. 
En seguimiento al artículo 24 del Estatuto del Tribunal, el 11 de mayo de 2010, el secretario general de la Autoridad Internacional de los Fondos Marinos transmitió a esa instancia jurisdiccional una nota, vía electrónica, por la que hacía de su conocimiento la decisión del Consejo de solicitar una opinión consultiva. El caso fue inscrito en el Registro del Tribunal como el Caso núm. 17 "Responsabilidades y obligaciones de los Estados que patrocinan personas y entidades respecto a actividades en la Zona". ${ }^{107}$

Acto seguido, y según establece el párrafo 1o. del artículo 133 del Reglamento del Tribunal, el secretario del Tribunal notificó la solicitud de opinión consultiva a todos los Estados parte de la Convemar. A la par, el presidente de la Sala decidió que todas aquellas organizaciones con estatus de observadores ante la Autoridad Internacional de los Fondos Marinos serían consideradas como "susceptibles de proporcionar informaciones sobre la cuestión” por lo que serían invitadas a participar en el procedimiento. ${ }^{108}$

De conformidad con el Artículo 131 del Reglamento, el Consejero jurídico de la Autoridad transmitió a la Sala un expediente que contenía los documentos, que a su juicio podían "servir para esclarecer el asunto". ${ }^{109}$

Posteriormente, 12 Estados Parte y 3 organizaciones, además de la Autoridad Internacional de los Fondos Marinos, presentaron sus exposiciones escritas sobre la cuestión. ${ }^{110} \mathrm{~A}$ fin de dar cumplimiento a lo

107 De conformidad con el artículo 24, Estatuto del Tribunal.

108 El presidente de la Sala es electo por los miembros de la misma, y desempeña su cargo durante los tres años que dura el mandato de los miembros de la Sala. Véanse $\S 3$ y 4 del artículo 36, Reglamento del Tribunal. Por su parte, los párrafos 2o., 3o. y 4o. del artículo 133 de las Reglas del Tribunal establecen la potestad del presidente de la Sala para identificar a estas organizaciones e invitarlas a participar en el procedimiento.

109 La parte pública de este expediente puede ser consultada en el sitio de Internet del Tribunal: www.itlos.org.

110 Los siguientes Estados Parte presentaron exposiciones escritas: Reino Unido, Nauru, República de Corea, Rumania, Países Bajos, Rusia, México, Alemania, China, Australia, Chile y Filipinas. Por su parte, las organizaciones que presentaron exposiciones escritas dentro del plazo fijado por el Presidente de la Sala fueron la Interoceanmetal Joint Organization y la International Union for Conservation of Nature and Natural Resources. Ello de conformidad con el párrafo 3o. del artículo 133 del Reglamento. Aunque recibida posteriormente a la fecha fijada por la Sala se incluyó, por decisión del presidente, en el expediente del caso la exposición escrita 
establecido en el Reglamento, todas las exposiciones y los documentos que las acompañan fueron transmitidos a esos Estados Parte y organizaciones, y luego publicados en el sitio de Internet del Tribunal. ${ }^{111} \mathrm{La}$ audiencia de la Sala se llevó a cabo el 14, 15 y 16 de septiembre de 2010. Realizaron presentaciones orales 9 Estados Parte y tres organizaciones. ${ }^{112}$

A continuación se examinarán los alegatos presentados por los Estados Parte y las organizaciones con estatus de observador, tanto en las exposiciones escritas como en las presentaciones orales, haciendo énfasis en lo relativo al trato especial y diferenciado para Estados en desarrollo cristalizado en Convemar y las responsabilidades y obligaciones de los Estados patrocinantes de actividades en la Zona.

\section{Los alegatos presentados en las exposiciones escritas y las intervenciones orales}

Las 15 exposiciones escritas presentadas a la Sala del Tribunal muestran un formato similar; inician examinando las cuestiones de la jurisdicción de la Sala así como lo relativo al derecho aplicable, para finalmente hacer algunos señalamientos breves sobre el fondo del asunto. Tomando en cuenta la temática que nos ocupa, y que las cuestiones procesales han sido ya examinadas a fondo en las secciones previas, nos centraremos aquí en los señalamientos relativos al trato especial y diferenciado para Estados en desarrollo y su relación directa con las obligaciones y res-

presentada por el Programa de Naciones Unidas para el Medio Ambiente. Cabe resaltar que el Tribunal también recibió una exposición escrita conjunta de las organizaciones no gubernamentales Stitching Greenpeace Council (Greenpeace) y WorldWide Fund for Nature (WWF), junto con una solicitud para participar en el procedimiento como amici curiae. Si bien la Sala del Tribunal decidió no aceptar la solicitud, su exposición escrita fue transmitida a los Estados y organizaciones y publicada por separado en el sitio de Internet del Tribunal.

111 Artículos 133(3) y 134, Reglamento. Véase www.itlos.org.

112 Se presentaron ante la Sala: la Autoridad Internacional de los Fondos Marinos, Alemania, Países Bajos, Argentina, Chile, Fiji, México, Nauru, Reino Unido, Rusia, la Comisión Oceanográfica Intergubernamental de la UNESCO y la International Union for Conservation of Nature and Natural Resources. 
ponsabilidades de los Estados en desarrollo patrocinantes de actividades en la Zona.

No obstante, es necesario reconocer desde un inicio que pocos son los señalamientos explícitos al trato especial y diferenciado para Estados en desarrollo. De forma general, esta cuestión es abordada accesoriamente en relación con las obligaciones de los Estados patrocinantes, independientemente de cualquier otra consideración.

Sin lugar a dudas, una de las cuestiones que determinan en gran medida la percepción de los Estados sobre esta cuestión es la necesidad imperiosa de salvaguardar el medio marino. Es evidente que de forma general esta necesidad parece primar sobre cualquier consideración relativa al trato especial y diferenciado.

No obstante, resulta importante señalar que ninguno de los Estados participantes negó la existencia de disposiciones en las que Convemar cristalizó el trato especial y diferenciado para Estados en desarrollo; por el contrario, todas ellos lo reconocieron. No obstante, y como veremos a continuación, en su mayoría consideraron que el trato especial y diferenciado previsto en Convemar estaba limitado a lo explícitamente establecido en las disposiciones de la misma Convención, por lo que en ningún caso cubría lo relativo a las obligaciones y responsabilidades de los Estados patrocinantes.

Este razonamiento es evidente, por ejemplo, en la exposición escrita de Australia, en la que se señala que:

as a matter of general principle, it is Australia's view that there should be no lacuna in responsibility and liability for damage caused by operations in the Area. If damage is caused by activities undertaken pursuant to Part XI, particularly to the environment, there should always be an entity which bears responsibility and liability for that damage. That entity could be the Authority, the contractor and/ or the sponsoring State Party ... the provisions of the Convention concerning responsibility and liability for damage caused by activities in the Area apply equally to all States Parties. The degree of protection to the Area, forming as it does part of the common heritage of mankind, does not vary according to the status of the State Party sponsoring an activity ... it cannot have been envisaged by those drafting the Convention that the level of environmental protection required of a 
contractor by a sponsoring State Party would vary according to the status of that State Party. ${ }^{113}$

\section{Una opinión muy similar fue expresada por la International Union for Conservation of Nature and Natural Resources, pues señaló que:}

The Convention promotes developing State participation in the Area to the extent specifically provided for in Part XI, including economic assistance and transfer of technology. However, the specific support for developing State participation does not include diminished responsibility in the context of sponsorship of activities in the Area. (Articles 148 and 152). [paras. 58 to 60] ... Articles 148 and 152(2) do not diminish the responsibility for developing states to comply with Part XI when sponsoring activities in the Area. They cannot therefore be read as setting a lower (or differentiated) threshold of compliance for developing states under the Convention. ${ }^{114}$

Si bien Alemania señaló igualmente en su exposición que "The protection of the Areas as the common heritage of mankind (Art. 136 of the Convention) has to be considered of paramount importance", ${ }^{115}$ no obstante, hizo una distinción importante entre la igualdad en el estándar de responsabilidad de todos los Estados patrocinantes, y la posibilidad de establecer diferentes derechos y obligaciones a fin de incorporar en la norma las circunstancias particulares de los Estados parte:

$113 \$ 20-21$, "Written Statement of Australia”, 19 de agosto de 2010. En el mismo sentido, Países Bajos señaló, durante su intervención oral ante el Tribunal que "The protection of the interests of mankind requires the observance of an identical degree of diligence by all States. The lack of technical capacity to regulate deep seabed mining may not justify a differential treatment that may impair the interests of mankind". Véase "Verbatim Record, Public sitting held on Tuesday", 15 September 2010, at 3.00 p.m. at the International Tribunal for the Law of the Sea, Hamburg, President of the Seabed Disputes Chamber, Judge Tullio Treves, presiding, Responsibilities and Obligations of States Sponsoring Persons and Entities with respect to Activities in the International Seabed Area (Request for Advisory Opinion Submitted to the Seabed Disputes Chamber), ITLOS/PV.2010/2, p. 15.

$114 \$ 19$ y 59, "Written Statement of International Union for Conservation of Nature and Natural Resources, Commission on Environmental Law, Oceans, Coastal and Coral Reefs Specialist Group", 19 de agosto de 2010.

$115 \S 10$, "Written Statement of the Federal Republic of Germany", 18 de agosto de 2010. 
Germany holds that the same standard of due diligence must apply to all States as regards the adoption of "laws and regulations" (Art. 4 para. 4 of Annex III) and their implementation and enforcement. Since the latter admittedly requires considerable financial and personnel resources, this could ultimately constitute an obstacle to the effective participation of developing States in the Area... While the principle of sovereign equality of States requires equal treatment of States in terms of responsibility, it does not necessarily prohibit establishing different rights and obligations taking into account specific circumstances. The concept of common but differentiated responsibilities has come to be more and more accepted in international environmental law. However, whenever a distinction is made between the different capacities of States Parties to implement measures to prevent environmental damage, it is explicitly provided for [énfasis agregado]. ${ }^{116}$

De esta forma, no obstante que Alemania reconoció que la Convemar prevé un sistema para la promoción de la participación de los Estados en desarrollo en las actividades de la Zona, también dejo claro que, a su entender, este sistema no incluye una diferenciación en los estándares requeridos de "diligencia debida" ni de responsabilidad, por lo que las obligaciones de todos los Estados patrocinantes son las mismas. ${ }^{117}$

Esta diferenciación entre el trato especial y diferenciado para Estados en desarrollo explícitamente previsto en la Convemar, y los estándares relativos a la extensión de responsabilidad y obligaciones de los Estados en desarrollo que patrocinan actividades en la Zona, parece también ser la interpretación adoptada por Rusia, al señalar que:

the approach presupposing application of different standards of responsibility and liability to developed and developing States as a form of promotion of the latter would go beyond the principle introduced in the Article 148 as there is no such

116 Ibidem, $\$ 15$ y 16.

117 Alemania concluye su exposición escrita señalando que: "In sum, the Convention provides for a system of promoting the participation of developing States in the activities in the Area through redistributive measures and capacity-building, not through requiring or allowing for differentiates standards of due diligence and responsibility. Therefore the obligations under Part XI with regard to contractors operating in the Area are the same for all sponsoring States". Véase $§ 19$, Ibidem. 
provision in the Convention that refers to a special approach to the needs of developing States in terms of their responsibility or liability. ${ }^{118}$

De forma similar, el Reino Unido señala que si bien la Parte XI de la Convención contiene algunos artículos en los que se establece una “consideración especial para los Estados en desarrollo", ninguna de las disposiciones sobre responsabilidad y obligaciones de los Estados patrocinantes hace referencia explícita a un trato especial y diferenciado para esos Estados; por lo que a su entender estas disposiciones deberían ser aplicadas igualmente a los Estados en desarrollo y los demás Estados Parte. Sobre esta base, el Reino Unido señaló que "it would obviously be inappropriate if the level of protection of the Area, which is after all 'the common heritage of mankind'... should depend upon which group of States the sponsoring State belongs to". ${ }^{119}$

Por su parte, la Autoridad Internacional de los Fondos Marinos se sumó a esta interpretación de las disposiciones de la Convemar y del principio de trato especial y diferenciado para Estados en desarrollo cristalizado en ese instrumento, señalando en su intervención oral ante la Sala del Tribunal que:

118 \$, "Written Statement submitted by the Russian Federation concerning the Advisory Opinion by the Seabed Disputes Chamber in Accordance with Article 133, paragraph 3 of the Rules of Procedure of the International Tribunal on the Law of the Sea on the question of the legal responsibilities, obligations and liability of the Sponsoring States”, 17 de agosto de 2010. Rusia reiteró su interpretación durante su comparecencia ante el Tribunal, señalando que "the approach presupposing application of different standards of responsibility and liability to developed and/or developing States as a form of promotion of the latter would go beyond the principle introduced in Article 148, as there is no such provision in the Convention that refers to a special approach to the needs of developing States in terms of their responsibility or liability". Véase "Verbatim Record, Public sitting held on Tuesday", 16 September 2010, at 3.00 p.m. at the International Tribunal for the Law of the Sea, Hamburg, President of the Seabed Disputes Chamber, Judge Tullio Treves, presiding, Responsibilities and Obligations of States Sponsoring Persons and Entities with respect to Activities in the International Seabed Area, (Request for Advisory Opinion Submitted to the Seabed Disputes Chamber), ITLOS/PV.2010/4, p. 7.

$119 \$ 3.6$, "Written statement of the United Kingdom of Great Britain and Northern Ireland”, 29 de julio de 2010. En el mismo sentido Argentina señaló durante su comparecencia ante el Tribunal que "Nowhere does the Convention differentiate between the 'obligations' of developing States and of other States regarding sponsorship ... Because the obligation of the sponsoring State is one of 'due diligence', the burden appears to be equally onerous on developed and developing States". Véase "Verbatim Record, Public sitting held on Tuesday, 15 September 2010, at 3.00 p.m....”, cit., p. 18. 
there is nothing in Part XI or elsewhere in the Convention, or in the 1994 Agreement, to suggest that the obligations of sponsoring States vary in any way depending on their level of development. In several places Part XI does provide for special consideration to be given to the interests of developing States, but... in every case where this occurs it is qualified by the words as "specifically provided for in this Part" (that is, of course Part XI)... Whilst there is real substance in the special considerations to be accorded to developing States under these provisions, such as for example the right to apply to "reserved areas", nowhere is there any suggestion that the other provisions of Part XI, such as those relating to the protection of the marine environment, should be applied with any less rigour depending on the state of development of the State concerned. ${ }^{120}$

De lo anteriormente expuesto, es posible concluir que el principal motor de esta interpretación que limita el trato especial y diferenciado para Estados en desarrollo, parece ser evitar un régimen diferenciado de estándares de "debida diligencia” aplicable a los Estados Parte en función de su nivel de desarrollo, ya que esto afectaría la necesidad primordial de proteger la Zona como patrimonio común de la humanidad.

En opinión de Alemania, este régimen diferenciado de obligaciones de Estados patrocinantes "would encourage a system of "eco-tourism" or "sponsor shopping". In such a system, contractors —often subsidiaries of powerful mining companies from industrialized countriescould seek the sponsorship of States with lower due diligence standards in order to avoid stricter standards and control". ${ }^{121}$

Sobre esta base, los Estados que apoyaban esta interpretación señalaron que si bien la Convemar reconocía las necesidades y los intereses especiales de los países en desarrollo, éste estaba limitado por el "texto de la Convención" a la promoción de su participación y a la consideración especial que les deberá prestar la Autoridad en los límites establecidos expresamente por la misma Convención:

120 Véase "Verbatim Record, Public sitting held on Tuesday", 14 September 2010, at 3.00 p.m. at the International Tribunal for the Law of the Sea, Hamburg, President of the Seabed Disputes Chamber, Judge Tullio Treves, presiding, Responsibilities and Obligations of States Sponsoring Persons and Entities with respect to Activities in the International Seabed Area (Request for Advisory Opinion Submitted to the Seabed Disputes Chamber), ITLOS/PV.2010/1, p. 13.

121 Véase "Verbatim Record, Public sitting held on Tuesday, 15 September 2010, at 3.00 p.m. ...”, cit., pp. 5 y 7. Rusia también hizo referencia al riesgo de crear un sistema de "sponso-shopping". 
Neither the Convention nor the Agreement contain specific provisions on the special needs and interests of developing countries with respect to their sponsorship of activities in the Area. Accepting divergent standards of diligence may produce perverse effects, undermining the general aim of ensuring that public-safety, health and environmental standards are met. ${ }^{122}$

Por el contrario, en su exposición escrita lamentablemente Nauru se limitó a señalar de forma somera la necesidad que el régimen normativo aplicable a las actividades en la Zona no perjudique a los Estados en desarrollo:

regarding State sponsorship responsibility... consideration must be given to the individual States' financial and technical capacities to regulate the activities of Contractors in the international seabed area. While developing States have no intention of evading responsibility; the regulatory regime governing the Area should not prejudice these States due to their degree of economic or scientific development.

On the contrary, developing States, particularly those least developed and lacking in natural resources, are the very States that are in most need of the benefits that will result from activities in the Area. To promote higher standards of living and conditions of economic progress in these States, the rules and regulations governing the Area, particularly those pertaining to sponsoring State responsibility, must not be interpreted and applied in such a way as to hinder and discourage developing State participation. ${ }^{123}$

Una posición muy similar, e igualmente falta de desarrollo, fue presentada por Filipinas, que únicamente señaló que, a su entender, "The lack of financial and technical capabilities should not hinder a country from participating in the activities in the Area. This is the true essence of the «common heritage of mankind»". ${ }^{124}$

122 Véase la intervención de Países Bajos en "Verbatim Record, Public sitting held on Tuesday, 15 September 2010, at 3.00 p.m. ...", cit., p. 15.

$123 \$ 15$ y 16, "Statement by the Republic of Nauru regarding the questions submitted to the Seabed Disputes Chamber for an advisory opinion on the responsibilities and obligations of States sponsoring entities with respect to activities in the international seabed area”, 5 de agosto de 2010 .

124 "Proposed Philippine Statements on the Request for Advisory Opinion submitted to the ITLOS Seabed Authority", p. 1. 
Sobre la base del conjunto de las intervenciones ante el Tribunal, es posible entonces señalar que, como lo hizo la Comisión Oceanográfica Intergubernamental de la Organización para la Educación, la Ciencia y la Cultura de las Naciones Unidas (Unesco/COI), el principio de trato especial y diferenciado para Estados en desarrollo:

... has produced specific and differentiated rights and obligations for developing countries explicitly set in the text of the Convention which aim to take into account their interest and protect the notion of common heritage of mankind.

The special and differential treatment for developing countries, explicitly provided for within the provisions themselves, have resulted in the incorporation into the legal norm the de facto differences between these and the rest of the State Parties to UNCLOS. ${ }^{125}$

Procedamos entonces a examinar la decisión que la Sala del Tribunal adoptó sobre la base de los alegatos presentados por los Estados y las organizaciones que participaron en el procedimiento.

\section{El examen del trato especial y diferenciado para los Estados en desarrollo en la Opinión del Tribunal}

La opinión consultiva de la Sala del Tribunal consta de 76 páginas en las que se analiza primeramente las cuestiones de jurisdicción, admisibilidad y el derecho aplicable, para posteriormente abocarse a responder las tres preguntas planteadas por el Consejo de la Autoridad Internacional de los Fondos Marinos.

Si bien la Opinión del Tribunal examina en detalle cada uno de los alegatos presentados por los Estados Parte y las organizaciones que participaron en el procedimiento, en relación a todos y cada uno de los temas que la solicitud del Consejo requería, nos limitaremos en esta sección a

\footnotetext{
125 Véase la intervención de la Comisión Oceanográfica Intergubernamental de la Organización de las Naciones Unidas para la Educación, la Ciencia y la Cultura en "Verbatim Record, Public sitting held on Tuesday", 16 September 2010, at 3.00 p.m. at the International Tribunal for the Law of the Sea, Hamburg, President of the Seabed Disputes Chamber, Judge Tullio Treves, presiding, Responsibilities and Obligations of States Sponsoring Persons and Entities with respect to Activities in the International Seabed Area (Request for Advisory Opinion Submitted to the Seabed Disputes Chamber)", ITLOS/PV.2010/4, p. 13.
} 
aquellas partes relativas al trato especial y diferenciado para Estados en desarrollo, mismas que se encuentran circunscritas a la respuesta de la primera pregunta planteada por la Autoridad.

En particular, es en el inciso VI de esta pregunta en la que la Opinión se aboca a examinar la cuestión de los "Intereses y necesidades de los Estados en desarrollo”. En este sentido, la Sala consideró de primordial importancia determinar el significado del artículo 148 de la Convemar.

Al respecto, la Sala observó que resulta esencial tomar en consideración que lo establecido en esta disposición en relación a la promoción de la participación efectiva de los Estados en desarrollo en las actividades en la Zona, teniendo debidamente en cuenta sus intereses y necesidades especiales, se encuentra supeditado, conforme a lo dispuesto en ese mismo artículo, a lo expresamente dispuesto en la Parte XI de la Convemar. ${ }^{126}$

A entender de la Sala, la frase "según se dispone expresamente en esta Parte", tiene como consecuencia que no sea posible considerar la existencia de una "cláusula general" que requiera la consideración de esos intereses y necesidades más allá de lo expresamente previsto en la Convención. ${ }^{127}$

Sobre esta base, la Sala determina que si bien existe un número considerable de disposiciones tendientes a dar satisfacción al 5o. párrafo preambular por el que se requiere tener particularmente en cuenta "los intereses y necesidades especiales de los países en desarrollo, sean ribereños o sin litoral”, no existe en la Convención disposición alguna que expresamente dicte un trato especial y diferenciado en materia de responsabilidad de los Estados patrocinantes cuando éstos sean Estados en desarrollo. ${ }^{128}$

Es por ello que concluye que las disposiciones generales relativas a las obligaciones y responsabilidades de los Estados patrocinantes "se aplican de la misma manera a todos los Estados patrocinantes, sean en desarrollo o desarrollados". ${ }^{129}$

126 §156, “Advisory Opinion, Seabed Disputes Chamber of the International Tribunal for the Law of the Sea, Case No. 17: Responsibilities and Obligations of States sponsoring persons and entities with respect to activities in the Area”, 1o. de febrero de 2011, p. 47.

127 Ibidem, $\$ 156$.

128 Ibidem, $\$ 157$ y 158 , pp. 47 y 48.

129 Ibidem, $§ 158$. 
Adicionalmente, la Sala señala que la igualdad de trato entre Estados patrocinantes, en desarrollo o desarrollados, es "consistente con la necesidad" de prevenir que empresas comerciales basadas en Estados desarrollados establezcan compañías en Estados en desarrollo, adquiriendo así la nacionalidad y el patrocinio de estos últimos, con la esperanza de estar sujetos a regulaciones y controles menos onerosos. ${ }^{130}$

En opinión de la Sala del Tribunal, una utilización generalizada del Estado patrocinante "de conveniencia" pondría en peligro la aplicación uniforme de los más altos estándares de protección del medio marino, el desarrollo seguro de las actividades en la Zona y la protección del patrimonio común de la humanidad. ${ }^{131}$

No obstante las conclusiones anteriores, en lo que parece ser un reconocimiento del papel central del trato especial y diferenciado para Estados en desarrollo en el marco de la Convemar, la Sala también observa en su Opinión, que no es posible excluir que "normas que establecen obligaciones directas para los Estados patrocinantes puedan prever un trato diferente para los Estados patrocinantes desarrollados y en desarrollo". ${ }^{132}$

Como ejemplo de lo anterior, la Opinión hace referencia a las disposiciones del Reglamento de nódulos en el que se señala la obligación de los Estados patrocinantes de aplicar el principio de precaución que figura en la Declaración de Río. A entender de la Sala de los Fondos Marinos, la aplicación por los Estados de este principio "de conformidad con sus capacidades", puede implicar un estándar más estricto para los Estados desarrollados que para aquellos en desarrollo. ${ }^{133}$

Adicionalmente, cabe resaltar que la Sala de los Fondos Marinos señala expresamente en su opinión consultiva que a fin de dar cabal cumplimiento a las disposiciones de la Convemar que prevén un trato especial y diferenciado para Estados en desarrollo en relación a las actividades en la Zona, es necesario que los Estados en desarrollo reciban "la necesaria asistencia técnica, incluyendo entrenamiento" a fin de que puedan participar efectivamente en esas actividades. ${ }^{134}$

\footnotetext{
130 Ibidem, $§ 159$.

131 Idem.

132 Ibidem, $\$ 160$.

133 Ibidem, $\$ 162$.

134 Ibidem, $\$ 163$.
} 
En este sentido, la Sala parece buscar un fino equilibrio entre el interés general de protección y preservación del medio marino, y el objeto y propósito asentado en el 5o. párrafo preambular, a saber el establecimiento de un orden jurídico para los mares y océanos que promueva los usos con fines pacíficos de los mares y océanos, la utilización equitativa y eficiente de sus recursos, el estudio, la protección y la preservación del medio marino y la conservación de sus recursos vivos, contribuyendo así a la "realización de un orden económico internacional justo y equitativo que tenga en cuenta los intereses y necesidades de toda la humanidad y, en particular, los intereses y necesidades especiales de los países en desarrollo, sean ribereños o sin litoral".

Prueba de ello es la búsqueda del acotamiento de la referencia al principio de responsabilidades comunes pero diferenciadas contenido en la Declaración de Río. Sin embargo, de forma velada, la Sala acaba reconociendo la relevancia del trato especial y diferenciado cristalizado en la Convemar, si bien excluyendo de su aplicación lo relativo a las obligaciones y responsabilidades de los Estados patrocinantes de actividades en la Zona: ${ }^{135}$

The provisions of the Convention which take into consideration the special interests and needs of developing States should be effectively implemented with a view to enabling the developing States to participate in deep seabed mining on an equal footing with developed States. ${ }^{136}$

\section{OBSERVACIONES FINALES}

Con esta opinión consultiva, la Sala de controversias de los Fondos Marinos concluyó el primer procedimiento de este tipo ante el Tribunal Internacional del Derecho del Mar. La opinión resulta particularmente relevante al considerar que las actividades en la Zona están apenas en sus primeras etapas, por lo que las consecuencias se harán patentes conforme estas actividades se desarrollen.

135 Idem.

136 Inciso 3, Parte Operativa, ibidem, p. 72. 
La interpretación de las disposiciones de Convemar que lleva a cabo la Sala de los Fondos Marinos es conforme con el artículo 31 de la Convención de Viena sobre el Derecho de los Tratados. La Opinión del Tribunal en su conjunto, y lo relativo al trato especial y diferenciado para Estados en desarrollo en particular, se hace sobre la base del principio de pacta sunt servanda contemplado igualmente en el artículo 26 de la misma Convención de Viena.

Es justamente sobre la base del principio de pacta sunt servanda que la determinación a la que llega la Sala del Tribunal sobre el alcance del principio de trato especial y diferenciado para Estados en desarrollo tiene importantes consecuencias en el contexto de la Convemar y del derecho internacional en general.

La conclusión de la Sala de los Fondos Marinos de excluir las obligaciones y responsabilidades de los Estados patrocinantes del alcance del trato especial y diferenciado para Estados en desarrollo resulta coherente con la cristalización de este principio en la Convemar.

Es decir que, como consta en la Opinión, resultaría improcedente otorgar a los Estados en desarrollo, sobre la base del trato especial y diferenciado previsto en la Convemar, un trato diferente en lo relativo a las responsabilidades y obligaciones de los Estados que patrocinan actividades en la Zona.

No obstante, y en ello radica la fina línea de equilibrio de la Opinión del Tribunal, esto de ninguna manera pone en tela de juicio ni el resto de las disposiciones de la Convención que plasman el principio de trato especial y diferenciado para Estados en desarrollo, ni el principio mismo, cuya cristalización puede igualmente constatarse en muchos otros instrumentos convencionales de áreas muy variadas de derecho internacional.

Por el contrario, la Sala reconoce explícitamente la inclusión en la norma jurídica que prevén algunas de las disposiciones de la Convemar, de las diferencias fácticas entre Estados en desarrollo y desarrollados. Sobre esta base, la Sala determina que las disposiciones de trato especial y diferenciado para Estados en desarrollo deben hacerse efectivas de forma tal que se permita a esos Estados participar en la minería de los Fondos Marinos en igualdad con los Estados desarrollados. 
De primordial relevancia resulta el reconocimiento por la Sala de los Fondos Marinos de la imposibilidad de excluir que "normas que establecen obligaciones directas para los Estados patrocinantes puedan prever un trato diferente para los Estados patrocinantes desarrollados y en desarrollo”. Al reconocer esta posibilidad, la Sala parece únicamente señalar que, a su entender, no resulta posible determinar que los Estados Parte de la Convemar hayan buscado establecer un trato especial y diferenciado para Estados en desarrollo en materia de obligaciones y responsabilidades de Estados patrocinantes.

Es precisamente con esta última parte de la Opinión de la Sala, que se recoge de forma coherente lo establecido en el 5o. párrafo preambular y en el resto de las disposiciones de trato especial y diferenciado de la Convemar.

No obstante, queda pendiente una importante tarea, misma que corresponderá llevar a cabo a la Autoridad Internacional de los Fondos Marinos; a saber: garantizar, sobre la base de la Opinión del Tribunal, que el conjunto de disposiciones de trato especial y diferenciado para Estados en desarrollo contenidas en Convemar se apliquen de forma tal que permitan el establecimiento de un sistema que garantice la viabilidad de actividades por Estados en desarrollo al tiempo de asegurar la protección y preservación del medio marino.

Esta tarea que abordará la Autoridad a partir de su próxima reunión en julio de 2011 promete ser compleja y fuente de considerables discusiones. 